\title{
Soil carbon stock in the tropical rangelands of Australia: Effects of soil type and grazing pressure, and determination of sampling requirement
}

\author{
M.J. Pringle a,*, D.E. Allen ${ }^{\text {a }}$, R.C. Dalal ${ }^{\text {a,b }}$, J.E. Payne ${ }^{\text {a }}$, D.G. Mayer ${ }^{c}$, P. O'Reagain ${ }^{\text {d }}$, B.P. Marchant ${ }^{\mathrm{e}}$ \\ a Landscape Sciences (ESP), DERM, GPO Box 2454, Brisbane, QLD, 4001, Australia \\ b Agriculture and Food Sciences, The University of Queensland, St Lucia, OLD, 4072, Australia \\ c Agri-Science Queensland (ESP), DEEDI, GPO Box 2454, Brisbane, QLD, 4001, Australia \\ d Agri-Science Queensland, DEEDI, PO Box 976, Charters Towers, QLD, 4820, Australia \\ e Rothamsted Research, Harpenden, Hertfordshire, AL5 2JQ UK
}

\section{A R T I C L E I N F O}

\section{Article history:}

Received 28 March 2011

Received in revised form 21 July 2011

Accepted 4 September 2011

Available online 2 November 2011

\section{Keywords:}

Carbon stock

Rangelands

Geostatistics

Residual maximum likelihood (REML)

Sampling

\begin{abstract}
A B S T R A C T
On-going, high-profile public debate about climate change has focussed attention on how to monitor the soil organic carbon stock $\left(C_{s}\right)$ of rangelands (savannas). Unfortunately, optimal sampling of the rangelands for baseline $C_{s}$ - the critical first step towards efficient monitoring - has received relatively little attention to date. Moreover, in the rangelands of tropical Australia relatively little is known about how $C_{\mathrm{s}}$ is influenced by the practice of cattle grazing. To address these issues we used linear mixed models to: (i) unravel how grazing pressure (over a 12-year period) and soil type have affected $C_{S}$ and the stable carbon isotope ratio of soil organic carbon $\left(\delta^{13} C\right.$ ) (a measure of the relative contributions of $C_{3}$ and $C_{4}$ vegetation to $C_{5}$ ); (ii) examine the spatial covariation of $C_{\mathrm{s}}$ and $\delta^{13} \mathrm{C}$; and, (iii) explore the amount of soil sampling required to adequately determine baseline $C_{\mathrm{s}}$. Modelling was done in the context of the material coordinate system for the soil profile, therefore the depths reported, while conventional, are only nominal.

Linear mixed models revealed that soil type and grazing pressure interacted to influence $C_{\mathrm{s}}$ to a depth of $0.3 \mathrm{~m}$ in the profile. At a depth of $0.5 \mathrm{~m}$ there was no effect of grazing on $C_{\mathrm{s}}$, but the soil type effect on $C_{\mathrm{s}}$ was significant. Soil type influenced $\delta^{13} \mathrm{C}$ to a soil depth of $0.5 \mathrm{~m}$ but there was no effect of grazing at any depth examined. The linear mixed model also revealed the strong negative correlation of $C_{\mathrm{s}}$ with $\delta^{13} \mathrm{C}$, particularly to a depth of $0.1 \mathrm{~m}$ in the soil profile. This suggested that increased $C_{s}$ at the study site was associated with increased input of $C$ from $C_{3}$ trees and shrubs relative to the $C_{4}$ perennial grasses; as the latter form the bulk of the cattle diet, we contend that $C$ sequestration may be negatively correlated with forage production. Our baseline $C_{\mathrm{s}}$ sampling recommendation for cattle-grazing properties of the tropical rangelands of Australia is to: (i) divide the property into units of apparently uniform soil type and grazing management; (ii) use stratified simple random sampling to spread at least 25 soil sampling locations about each unit, with at least two samples collected per stratum. This will be adequate to accurately estimate baseline mean $C_{\mathrm{s}}$ to within $20 \%$ of the true mean, to a nominal depth of $0.3 \mathrm{~m}$ in the profile.
\end{abstract}

Crown Copyright @ 2011 Published by Elsevier B.V. All rights reserved.

\section{Introduction}

On-going, high-profile public debate about climate change has focussed attention on how to monitor the soil organic carbon stock $\left(C_{\mathrm{s}}\right)$ of rangelands (savannas). It is hoped that, through monitoring $C_{\mathrm{s}}$, cattle graziers will benefit financially when they simultaneously sequester carbon in their soil and improve pasture productivity. Grazed landscapes are thought to have considerable potential for $C_{\mathrm{s}}$ storage. Furthermore, changes in grazing management that result in minor changes in soil $C$ might cause proportionately large changes in $C_{s}$ globally, due to the substantial area devoted to grazing (Derner and

\footnotetext{
* Corresponding author. Tel.: +61 731705680.

E-mail address: matthew.pringle@derm.qld.gov.au (M.J. Pringle).
}

Schuman, 2007). Superficially, the task of the soil scientist is simple: sample an area to establish baseline $C_{\mathrm{s}}$ then, after a lapse of time, re-sample the area to assess the change in $C_{\mathrm{s}}$. Unfortunately it is not so simple. In addition to the grazier's management preferences, carbon accumulation at the spatial scale of 'the paddock' (i.e. the smallest unit of management) will be influenced by the inherent soil variation, microclimate, fire history, topography, and the complexity of plant communities (Allen et al., 2010; Follett and Reed, 2010; Schuman et al., 2002). Each of these factors will interact over time, making it difficult to separate the respective contributions of environment and grazing management to the change in $C_{s}$.

In a recent global review Piñeiro et al. (2010) found that $C_{S}$ responds inconsistently to varied grazing conditions and environments. They identified changes in the composition of plant species as one of the key factors for understanding the net effect of grazing on $C_{\mathrm{s}}$. This agrees 
with other studies that have linked plant communities with grazing management (Bagchi and Ritchie, 2010; Derner and Schuman, 2007). The implication is that, as well as sampling for $C_{\mathrm{s}}$, the soil scientist might consider assessing the contributions of different plant groups to $C_{\mathrm{s}}$. In this regard the relative abundance of the ${ }^{13} \mathrm{C} /{ }^{12} \mathrm{C}$ isotopes of soil organic carbon (denoted $\delta^{13} \mathrm{C}$ ) is useful because it reflects the photosynthetic pathway $\left(C_{3}\right.$ or $\left.C_{4}\right)$ of the vegetation grown at a location, and consequently the proportional $C$ contribution to $C_{s}$ by vegetation type (Boutton et al., 1998; Ehleringer et al., 2000; Peterson and Fry, 1987). Typical values for $\delta^{13} C$ in soil under $C_{3}$ and $C_{4}$ vegetation are -11 to $-14 \%$ and -24 to $-30 \%$ respectively (Boutton et al., 1998).

We contend that a more complete understanding of belowground carbon dynamics in a grazing system will be attained by measuring the soil simultaneously for $C_{\mathrm{s}}$ and $\delta^{13} C$. Despite the large number of studies into the nature of $C_{\mathrm{s}}$ and $\delta^{13} \mathrm{C}$ in grazed land, information on their correlation is scarce in the literature. Several studies have examined the spatial variability of $C_{\mathrm{s}}$, with the aim of optimising a geostatistical sampling scheme for mapping (e.g. Rossi et al., 2009; Schöning et al., 2006; Worsham et al., 2010). The same attention has not been given to the spatial variability of $\delta^{13} C$. Powers (2006) investigated the spatial variability of $\delta^{13} C$ in an agricultural context. She reported that the product-moment correlation of $\delta^{13} \mathrm{C}$ with soil organic carbon concentration (n.b. not $C_{\mathrm{s}}$ ) for pasture was -0.28 , but in a nearby forest it was -0.77 . Her subsequent geostatistical analysis considered $\delta^{13} \mathrm{C}$ and soil organic carbon concentration as independent variables, and no formal inference was made about the effect of deforestation.

Our study had three aims: (i) to determine the effects of soil type and grazing pressure on $C_{\mathrm{s}}$ and $\delta^{13} C$; (ii) to examine the spatial covariation of $C_{\mathrm{s}}$ and $\delta^{13} C$; and, (iii) to determine future baseline sampling requirements for $C_{\mathrm{s}}$ and $\delta^{13} C$. As an adjunct to (ii), we wished to see whether it would be practical to map $C_{\mathrm{s}}$ and $\delta^{13} \mathrm{C}$ at a withinpaddock scale. To achieve these aims we used linear mixed models, described below, which allowed us to separate the effects of soil type from grazing pressure, while explicitly considering the spatial covariation of $C_{\mathrm{s}}$ and $\delta^{13} \mathrm{C}$. The focus of our study is a grazing-strategy trial based in the rangelands of tropical Australia, which has been running since 1997 . The relatively long-term nature of this trial, together with the detailed soil data available, suggested its suitability.

\section{Statistical background to the linear mixed model}

Let us say that, for an area of interest, we have collected $n_{1}$ observations of soil variable $z_{1}$, and $n_{2}$ observations of soil variable $z_{2}$. Both have been sampled systematically on a grid. Note that it is not necessary that $n_{1}=n_{2}$.

Under a probabilistic ('design-based'-see de Gruijter et al., 2006) sampling design we could conventionally analyse the data with a linear model, fitted with the least-squares method. However, if a systematic, rather than a probabilistic, framework has been used to locate the soil samples, least-squares modelling results in biased estimates of variance, which in turn biases any inference derived from the model. The way to circumvent this problem is through 'model-based' analysis (de Gruijter et al., 2006). The linear mixed model (LMM) is the model-based equivalent of a linear model. The essential difference between design-based and model-based methods is that the latter considers explicitly the spatial correlation of $z_{1}$ with $z_{2}$. Thus the geostatistical concept of the variogram (Matheron, 1963) is central to model-based analysis. The Matérn function is considered to be a general form of variogram (Minasny and McBratney, 2005). For $z_{1}$ it will be:

$\gamma_{1,1}(h)=b_{1,1}^{0}+b_{1,1}^{1}\left\{1-\frac{1}{2^{v-1} \Gamma(v)}\left(\frac{h}{r}\right)^{v} K_{v}\left(\frac{h}{r}\right)\right\}$

where $\gamma_{1,1}(h)$ indicates the semivariance of $z_{1}$ as a function of separation distance, $h ; b_{1,1}^{0}$ (where ' 0 ' is an index, not a power) is known as 'nugget' variance (i.e. spatially independent variation); $b_{1,1}^{1}$ (where superscript ' 1 ' is an index) is the spatially autocorrelated variance; $r$ is a distance parameter $(r>0) ; v$ is a smoothness parameters $(v>0)$; and $K_{v}$ is a modified Bessel function of the second kind, of order $v$. Parameters $r$ and $v$ define the effective range of the variogram, i.e. the separation distance where $\gamma_{1,1}$ reaches $95 \%$ of $b_{1,1}^{0}+b_{1,1}^{1}$. Substitution of the relevant subscripts into Eq. (1) yields the auto-variogram for $z_{2}$, or the cross-variogram of $z_{1}$ and $z_{2}$.

Marchant and Lark (2007) demonstrated how to implement a LMM when there are two or more response variables. Pringle et al. (2008a,b) applied these methods to analyse, in a spatial context, how the predictions of process models corresponded with observed data. The response variables are joined to form the length- $\left(n_{1}+n_{2}\right)$ vector $\mathbf{z}=\left(\mathbf{z}_{1}^{T}, \mathbf{z}_{2}^{T}\right)^{T}$. The general form of the LMM is:

$\mathbf{z}=\mathbf{X} \boldsymbol{\beta}+\mathbf{u}$,

where $\mathbf{X}$ is a $\left(n_{1}+n_{2}\right) \times f$ design matrix that contains the values at each location of the $f$ quantities which vary linearly with $\mathbf{z}$; the length- $f$ vector $\beta$ contains the parameters that describe the deterministic relation between $\mathbf{X}$ and $\mathbf{z}$; and the length- $\left(n_{1}+n_{2}\right)$ vector $\mathbf{u}$ contains a realisation of a second-order stationary, normally distributed, spatially correlated random function, $U$. Thus $\mathbf{z}$ is the sum of a deterministic component (the 'fixed effects' or 'trend'), and a random component (the 'random effects'). An $\left(n_{1}+n_{2}\right) \times\left(n_{1}+n_{2}\right)$ covariance matrix, $\mathbf{V}$, describes the variation of $\mathbf{u}$. The elements of $\mathbf{V}$ are determined by variogram parameters. For $k$ response variables there will be $k(k+1) / 2$ variograms; for $k=2$ there will be two auto-variograms and one cross-variogram. Central to the method of Marchant and Lark (2007) is that the auto- and cross-variogram parameters form a linear model of coregionalisation (LMCR). For two response variables the LMCR requires that (Webster and Oliver, 2001):

$$
\begin{aligned}
& b_{1,1}^{q} \geq 0 \\
& b_{2,2}^{q} \geq 0 \\
& \left|b_{1,2}^{q}\right| \leq \sqrt{b_{1,1}^{q} b_{2,2}^{q}},
\end{aligned}
$$

for all $q$, where $q=(0,1)$ according to the Matérn function (Eq. (1)). Additionally, we need to ensure that the respective values of $r$ and $v$ are common to all auto- and cross-variograms, and that, together, they confer a sensible effective range. Under the LMCR the elements of $\mathbf{V}$ are given by:

$$
\begin{array}{ll}
\mathbf{V}_{i, j}=b_{1,1}^{0}+b_{1,1}^{1}-\gamma_{1,1}(\mathrm{~h}) & \text { if } \mathrm{z}(i) \in \mathbf{z}_{1} \text { and } z(j) \in \mathbf{z}_{1} \\
\mathbf{V}_{i, j} \text { and } \mathbf{V}_{j, i}=b_{1,2}^{0}+b_{1,2}^{1}-\gamma_{1,2}(h) & \text { if } \mathrm{z}(i) \in \mathbf{z}_{1} \text { and } z(j) \in \mathbf{z}_{2}, \\
\mathbf{V}_{i, j}=b_{2,2}^{0}+b_{2,2}^{1}-\gamma_{2,2}(h) & \text { if } \mathrm{z}(i) \in \mathbf{z}_{2} \text { and } z(j) \in \mathbf{z}_{2}
\end{array}
$$

where $i$ and $j$ respectively relate a particular row and column of $\mathbf{V}$.

Under the assumption that $U$ is normally distributed the residual log-likelihood of the data conditional on the parameters of Eq. (2), i.e. $\boldsymbol{\beta}$ and $\boldsymbol{\theta}=\left(b_{1,1}^{0}, b_{1,2}^{0}, b_{2,2}^{0}, b_{1,1}^{1}, b_{1,2}^{1}, b_{2,2}^{1}, r, v\right)$ is:

$$
l_{R}(\boldsymbol{\theta}, \mathbf{X}, \mathbf{S z})=c(\mathbf{X})-\frac{1}{2} \log |\mathbf{V}|-\frac{1}{2} \log \left|\mathbf{X}^{\mathrm{T}} \mathbf{V}^{-1} \mathbf{X}\right|-\frac{1}{2}(\mathbf{z}-\mathbf{X} \boldsymbol{\beta})^{\mathrm{T}} \mathbf{V}^{-1}(\mathbf{z}-\mathbf{X} \boldsymbol{\beta}) .
$$

Note that the term $\mathbf{S z}$ (where $\mathbf{S X}=0$ and $\operatorname{rank}(\mathbf{S})=\left(n_{1}+n_{2}\right)-$ $\operatorname{rank}(\mathbf{X})$ ) shows that $\mathbf{z}$ has been projected into a residual space where the fixed effects have zero expectation. This reduces bias in $\boldsymbol{\theta}$ relative to conventional log-likelihood estimation (Lark and Cullis, 2004). The term $c(\mathbf{X})$ is constant for a particular form of the design matrix. Vector $\boldsymbol{\beta}$ is derived from generalised least squares:

$\boldsymbol{\beta}=\left(\mathbf{X}^{\mathrm{T}} \mathbf{V}^{-1} \mathbf{X}\right)^{-1} \mathbf{X}^{\mathrm{T}} \mathbf{V}^{-1} \mathbf{z}$ 
The values of $\boldsymbol{\theta}$ that maximise $l_{R}(\boldsymbol{\theta}, \mathbf{X}, \mathbf{S z})$ are taken to represent the best estimate for the LMM. Hence the term 'residual maximum likelihood' (REML), the derivation of which was presented originally by Patterson and Thompson (1971). In practice $l_{R}(\boldsymbol{\theta}, \mathbf{X}, \mathbf{S z})$ is generally multiplied by -1 and minimised.

\subsection{Selecting the most appropriate fixed effects}

It is good practice to fit a variety LMMs with different numbers of fixed effects, and then choose the most parsimonious combination for z. In the context of likelihood estimators the choice is aided by likelihood ratio tests that determine whether particular terms in the fixed effects justify inclusion. We assume that a LMM contains two nested groups of fixed effects such that $\boldsymbol{\beta}=\left(\boldsymbol{\beta}_{0}, \boldsymbol{\beta}_{1}\right)$, and $\mathbf{X}=\left(\mathbf{X}_{0}, \mathbf{X}_{1}\right)$. If the expected value of the 'full' model is $E[\mathbf{z}]=\mathbf{X} \boldsymbol{\beta}$ and the expected value of the 'reduced' model is $E[\mathbf{z}]=\mathbf{X}_{0} \boldsymbol{\beta}_{0}$, then the decision whether to include $\beta_{1}$ in the LMM is based on the difference between the likelihoods. However, with REML, $\mathbf{z}$ undergoes different projections depending on the design matrix, therefore direct comparisons of likelihoods based on different $\mathbf{X}$ matrices are not valid. Welham and Thompson (1997) found a way to address this problem. First, the residual log-likelihood is maximised for the full complement of fixed effects (Eq. (4)). Next, the residual log-likelihood is maximised for the full complement of fixed effects using a modification of Eq. (4):

$$
\begin{aligned}
l_{R}\left(\boldsymbol{\theta}_{0}, \mathbf{X}_{0}, \mathbf{S z}\right)= & c(\mathbf{X})-\frac{1}{2} \log |\mathbf{V}|-\frac{1}{2} \log \left|\mathbf{X}^{\mathrm{T}} \mathbf{V}^{-1} \mathbf{X}\right|- \\
& \frac{1}{2}\left(\mathbf{z}-\mathbf{X}_{0} \boldsymbol{\beta}_{0}+\mathbf{X}_{1} \boldsymbol{\beta}_{1}\right)^{\mathrm{T}} \mathbf{V}^{-1}\left(\mathbf{z}-\mathbf{X}_{0} \boldsymbol{\beta}_{0}+\mathbf{X}_{1} \boldsymbol{\beta}_{1}\right)
\end{aligned}
$$

where, crucially, $\boldsymbol{\beta}_{1}=\mathbf{0}$ and is held constant. The residual loglikelihood test statistic is:

$D=-2\left\{l_{R}\left(\boldsymbol{\theta}_{0}, \mathbf{X}_{0}, \mathbf{S z}\right)-l_{R}(\boldsymbol{\theta}, \mathbf{X}, \mathbf{S z})\right\}$.

This gives a likelihood ratio for the null hypothesis that $\boldsymbol{\beta}_{1}=\mathbf{0}$, with $D$ approximated by a chi-squared distribution with $g$ degrees of freedom, where $g$ is the number of fixed effects in $\beta_{1}$. If $D$ is greater than the inverse chi-squared distribution at a probability of $P=0.05$, with $g$ degrees of freedom, then $\beta_{1}$ justifies inclusion in the LMM.

\subsection{Cross-validation of the LMM}

Having fitted an appropriately parsimonious LMM we use crossvalidation to check the plausibility of the assumption that $U$ is normally distributed. To cross-validate, we visit each observed location in $\mathbf{z}$ successively and use the EBLUP - an analogue of universal kriging (Lark et al., 2006) - to predict the value as if the location had not been sampled. For each location we then compute the standardised squared prediction error (Webster and Oliver, 2001). At the $i^{\text {th }}$ location of, for example, $z_{1}$ this is:

$\theta_{1, i}=\left(z_{1, i}-\hat{z}_{1, i}^{-}\right)^{2} / \hat{\sigma}_{1, i}^{2}$,

where $\hat{z}_{1, i}^{-}$is the EBLUP prediction of $z_{1}$ at the $i^{\text {th }}$ location when this sample is withheld from $\mathbf{z}$, and $\hat{\sigma}_{1, i}^{2}$ is the EBLUP estimation variance. If $\mathbf{u}$ is indeed multivariate normal then $\theta_{1}$ across all $n_{1}$ locations will have a chi-squared distribution with one degree of freedom. The expected median $\left(\tilde{\theta}_{1}\right)$ of this distribution will be 0.455 (Lark, 2000). We can create a confidence interval about this value by simulating many realisations of multivariate normal variables based on the parameters of the LMM, and then computing $\tilde{\theta}_{1}$ for each realisation, to build a probability distribution. If $\tilde{\theta}_{1}$ of the observed data is outside the bootstrapped confidence interval (as defined from the probability distribution) it indicates that $z_{1}$ is not multivariate normal, probably due to the presence of outlying values.

\subsection{Structural correlations}

A useful by-product of the LMCR is the structural correlation of the response variables:

$b_{1,2}^{q} / \sqrt{b_{1,1}^{q} b_{2,2}^{q}}$

where, as before, $q=(0,1)$. Structural correlations are analogous to the conventional product-moment correlation, with the advantage that they indicate the strength of the relationship at particular nested spatial scales.

\section{Methods}

\subsection{Study site}

The study site forms part of a long-term cattle-grazing trial at Wambiana station $\left(20^{\circ} 34^{\prime} \mathrm{S}, 146^{\circ} 07^{\prime} \mathrm{E}\right), 70 \mathrm{~km}$ southwest of Charters Towers, north Queensland, Australia. Median annual rainfall for Trafalgar station, about $20 \mathrm{~km}$ from the study site, is $617 \mathrm{~mm}$ (19102010). About two-thirds of the annual rainfall is received between December and March (the summer months), but is extremely variable from year to year: for January and February the historical 1st decile of rainfall is $<30 \mathrm{~mm}$, but the 9th decile is $>250 \mathrm{~mm}$.

The grazing trial was conceived to investigate appropriate stocking strategies in open savanna, given such unreliable rainfall (O'Reagain and Bushell, 1999). Ten paddocks of $92-115$ ha are arranged as a randomised block design with two replicates of five treatments. In 1997 when the trial commenced, each paddock was randomly allocated to one of five grazing treatments (for more details see O'Reagain et al., 2009, 2011). For the purpose of this study the two treatments with the greatest contrast in grazing pressure were selected. These were the 'heavy' and 'light' stocking-rate treatments. Since the trial commenced the average heavy stocking rate has been $5.41 \mathrm{ha}$ /animal equivalent (defined as a 450-kg steer), and $9.03 \mathrm{ha}$ /animal equivalent for the light stocking rate (O'Reagain et al. 2009). Those responsible for running the trial have recently deferred the term 'light' in favour of 'moderate' because it actually reflects the long-term sustainable carrying capacity of the study area (O'Reagain et al., 2011). In line with this recommendation we use 'moderate' herein.

The paddocks of the grazing trial are configured to share similar proportions of the main soil-vegetation associations of the area (Table 1). At the start of the grazing trial a soil survey was conducted using the soil associations defined by Rogers et al. (1999), but at a finer scale than that original mapping. The dominant soil map unit is actually a soil complex (Gunn et al., 1988) comprising brown sodosol and yellow kandosol (Isbell, 2002). Although palatability of the vegetation depends on growth stage and rainfall, the $C_{4}$ tropical grasses are generally considered more palatable than $C_{3}$ species, i.e. the trees and shrubs. Accordingly, grasses form by far the bulk of the cattle diet, although $C_{3}$ woody species are browsed in the late dry season.

\subsection{Soil sampling}

We sampled the soil intensively from one replicate each of the moderate and heavy stocking treatments (Fig. 1). The chosen pair of treatments shared a common boundary, which minimised travelling distances. To ensure that we represented each combination of grazing treatments and soil types adequately, and to learn about the patterns of spatial variation, we devised a set of nested grids. These grids implied that model-based analysis with a LMM would be needed to estimate variance components. At the coarsest scale of nesting, soil samples were collected at the nodes of a $250-\mathrm{m} \times 200$-m grid, overlaid on each grazing treatment. Forty-six soil samples were collected 
Table 1

General information for the soil and vegetation of the study site.

\begin{tabular}{|c|c|c|c|c|c|c|c|}
\hline \multirow{2}{*}{$\begin{array}{l}\text { Australian soil } \\
\text { classification }^{\mathrm{a}}\end{array}$} & \multirow{2}{*}{$\begin{array}{l}\text { World reference } \\
\text { base }^{\text {b }}\end{array}$} & \multirow{2}{*}{$\begin{array}{l}\text { Soil } \\
\text { association }^{c}\end{array}$} & \multirow[t]{2}{*}{ Dominant vegetation } & \multirow{2}{*}{$\begin{array}{l}\text { Photosynthetic } \\
\text { pathway }\end{array}$} & \multicolumn{3}{|c|}{$\delta^{13} \mathrm{C}(\%)$ in the... } \\
\hline & & & & & $\overline{\text { root }}$ & leaf & twig \\
\hline \multirow[t]{4}{*}{ Brown sodosol } & Solonetz & Liontown & Eucalyptus brownii & $\mathrm{C}_{3}$ & & $-27.5^{\mathrm{e}}$ & $-26.5^{\mathrm{e}}$ \\
\hline & & & Carissa ovata & $\mathrm{C}_{3}$ & & & $-26.1^{\mathrm{e}}$ \\
\hline & & & Chrysopogon fallax & $\mathrm{C}_{4}$ & $-13.0^{\mathrm{d}}$ & $-12.8^{\mathrm{d}}$ & \\
\hline & & & Bothriochloa ewartiana & $\mathrm{C}_{4}$ & $-12.6^{\mathrm{e}}$ & $-13.9^{\mathrm{e}}$ & \\
\hline \multirow[t]{5}{*}{ Yellow kandosol } & Ferralsol & Boston & Eucalyptus melanophloia & $\mathrm{C}_{3}$ & & $-28.1^{\mathrm{e}}$ & $-26.3^{\mathrm{e}}$ \\
\hline & & & Eriachne mucronata & $\mathrm{C}_{4}$ & & & \\
\hline & & & Aristida spp. & $\mathrm{C}_{4}$ & $-14.3^{\mathrm{d}}$ & $-13.9^{\mathrm{d}}$ & \\
\hline & & & Chrysopogon fallax & $\mathrm{C}_{4}$ & $-13.0^{\mathrm{d}}$ & $-12.8^{\mathrm{d}}$ & \\
\hline & & & Heteropogon contortus & $\mathrm{C}_{4}$ & $-13.1^{\mathrm{d}}$ & $-13.3^{\mathrm{d}}$ & \\
\hline Red kandosol & Ferralsol & Rangeside & (As for Yellow kandosol) & & & & \\
\hline \multirow[t]{6}{*}{ Grey vertosol } & Vertosol & Powlathanga & Acacia harpophylla & $\mathrm{C}_{3}$ & & & \\
\hline & & & Eucalyptus brownii & $\mathrm{C}_{3}$ & & $-27.5^{\mathrm{e}}$ & $-26.5^{\mathrm{e}}$ \\
\hline & & & Carissa ovata & $\mathrm{C}_{3}$ & & & $-26.1^{\mathrm{e}}$ \\
\hline & & & Dicanthium sericeum & $\mathrm{C}_{4}$ & & & \\
\hline & & & Bothriochloa ewartiana & $\mathrm{C}_{4}$ & $-12.6^{\mathrm{e}}$ & $-13.9^{\mathrm{e}}$ & \\
\hline & & & Eulalia aurea & $\mathrm{C}_{4}$ & & & \\
\hline
\end{tabular}

a Isbell (2002).

b IUSS Working Group WRB (2007).

c Rogers et al. (1999).

d Krull and Bray (2005).

e Bray et al. (2006).

at this scale (i.e. 2 grazing treatments $\times 23$ locations). For the intermediate scale of nesting we placed a $100-\mathrm{m} \times 100-\mathrm{m}$ square within the polygon that defined each combination of grazing treatment and soil type. We then subdivided each square into 25 cells of equal area, and collected one sample at the centre of each cell. A total of 150 soil samples were collected at this scale ( 2 grazing treatments $\times 3$ soil types $\times 25$ locations). One sample location from the 1-ha square was used as a starting point for the finest scale of nesting. This location formed one corner of a $25-\mathrm{m} \times 25$-m square, which was subdivided into 25 cells of equal area, with one sample collected at the centre of each. A total of 144 soil samples were collected at this scale ( 2 grazing treatments $\times 3$ soil types $\times 24$ locations). At four of the five sample locations along a diagonal of the $25-\mathrm{m} \times 25-\mathrm{m}$ square we took further samples on exponentially spaced transects (Pettitt and McBratney, 1993). The sample intervals for these transects were $0.1 \mathrm{~m}, 0.25 \mathrm{~m}, 0.5 \mathrm{~m}$, and $1 \mathrm{~m}$. A total of 96 samples were collected in this way ( 2 grazing treatments $\times 3$ soil types $\times 4$ locations $\times 4$ intervals). The spatial arrangement of the sampled locations is illustrated in Fig. 1. A total of 436 locations were sampled.

Samples were collected in March-April 2009 using 0.042-0.044-m internal diameter soil coring tubes, driven by a hydraulically operated rig, to a maximum depth of $0.5 \mathrm{~m}$. Where the rig was unable to reach $0.5 \mathrm{~m}$ due to an impenetrable layer the ultimate depth of the core was noted. If the rig could not be positioned at the intended location due to a tree, sampling was undertaken as close by as possible. A differential Global Positioning System was used to georeference the sampled locations. Each core was divided into four depth intervals: $0-0.1 \mathrm{~m}$, $0.1-0.2 \mathrm{~m}, 0.2-0.3 \mathrm{~m}$, and $0.3-0.5 \mathrm{~m}$. The soil sample associated with each depth interval was bagged in situ, thus producing a total of 1744 samples (herein, the term 'sample' denotes the soil associated with one depth layer within one core). All soil samples were stored at approximately $25{ }^{\circ} \mathrm{C}$ or cooler until the end of the sampling campaign. They were then transferred at ambient air temperature to Brisbane, and refrigerated until processing. The time between collection and processing was approximately three weeks.

\subsection{Laboratory analyses}

Samples were air-dried at $40{ }^{\circ} \mathrm{C}$ then ground to pass through a 2mm sieve. Soil pH (1:5 water) was measured according to the method of Rayment and Higginson (1992). If, within a particular soil type, any observed $\mathrm{pH}$ values were $>7$ then all samples associated with that soil type were treated with $\mathrm{HCl}$ to remove carbonate-carbon (Fernandes and Krull, 2008). The $<2-\mathrm{mm}$ fraction of soil was sub-sampled and fine-ground $(<0.1 \mathrm{~mm})$ to determine organic $C$ concentration (units of \%) and natural abundance ${ }^{13} \mathrm{C}$ values. Analysis was undertaken using an Isoprime isotope ratio mass spectrometer (IRMS), coupled to a Eurovector elemental analyser (Micromass Isoprime-Eurovector EA 3000). Approximately $20 \mathrm{mg}$ of the fine-ground soil was weighed into an $8-\mathrm{mm} \times 5-\mathrm{mm}$ tin $(\mathrm{Sn})$ capsule and analysed against a known set of standards (Acetanilide chemical standard for organic C, and ANU Sucrose for ${ }^{13} \mathrm{C}$ ). The ratio of ${ }^{13} \mathrm{C}$ in the soil relative to the ${ }^{13} \mathrm{C}$ in a Pee Dee Belemnite standard (Craig, 1953), in units of parts per thousand (\%), was computed as:

$\delta^{13} C=\left(R_{\text {soil }} / R_{\text {standard }}-1\right) \times 1000$,

where $R$ was the molar ratio of ${ }^{13} \mathrm{C} /{ }^{12} \mathrm{C}$ (Ehleringer et al., 2000).

The $\geq 2-\mathrm{mm}$ fraction of soil comprised gravel and Fe-Mn concretions. These components were separated visually then weighed. For 10 randomly selected samples we crushed the gravel and Fe-Mn concretions to $<0.1 \mathrm{~mm}$, then measured each for organic $\mathrm{C}$ as above. The total soil organic C concentration (units of \%) of each sample was calculated as:

$$
\begin{aligned}
C= & \left(\bar{C}_{\text {gravel }} \times m_{\text {gravel }}+\bar{C}_{\mathrm{Fe}-\mathrm{Mn}} \times m_{\mathrm{Fe}-\mathrm{Mn}}+C_{<2-\mathrm{mm}} \times m_{<2-\mathrm{mm}}\right) \\
& /\left(m_{\text {gravel }}+m_{\mathrm{Fe}-\mathrm{Mn}}+m_{<2-\mathrm{mm}}\right),
\end{aligned}
$$

where: $\bar{C}_{\text {gravel }}$ and $\bar{C}_{\mathrm{Fe}-\mathrm{Mn}}$ were the mean concentrations of organic $\mathrm{C}$ in the gravel and Fe-Mn concretions respectively; $C_{<2-\mathrm{mm}}$ was the concentration of organic $C$ in the $<2-\mathrm{mm}$ fraction of soil; and $m_{\text {gravel }}$, $m_{\mathrm{Fe}-\mathrm{Mn}}$ and $m_{<2-\mathrm{mm}}$ were the mass of each fraction in the sample.

Bulk density ( $\rho$, units of $\mathrm{Mg} \mathrm{m}^{-3}$ ) was determined following the procedure of Linn and Doran (1984). A sub-sample of each sample was used to measure the paddock-moist weight. Following drying for 3 days at $105^{\circ} \mathrm{C}$ the sub-sample was measured for oven-dry weight, with $\rho$ estimated as the mass of the oven-dry soil divided by the volume of the soil core at the depth interval of the sample.

\subsection{Material coordinate system}

Gifford and Roderick (2003) and McBratney and Minasny (2010) recommended reporting $C_{\mathrm{s}}$ as a function of soil mass (i.e. in a 
(a)

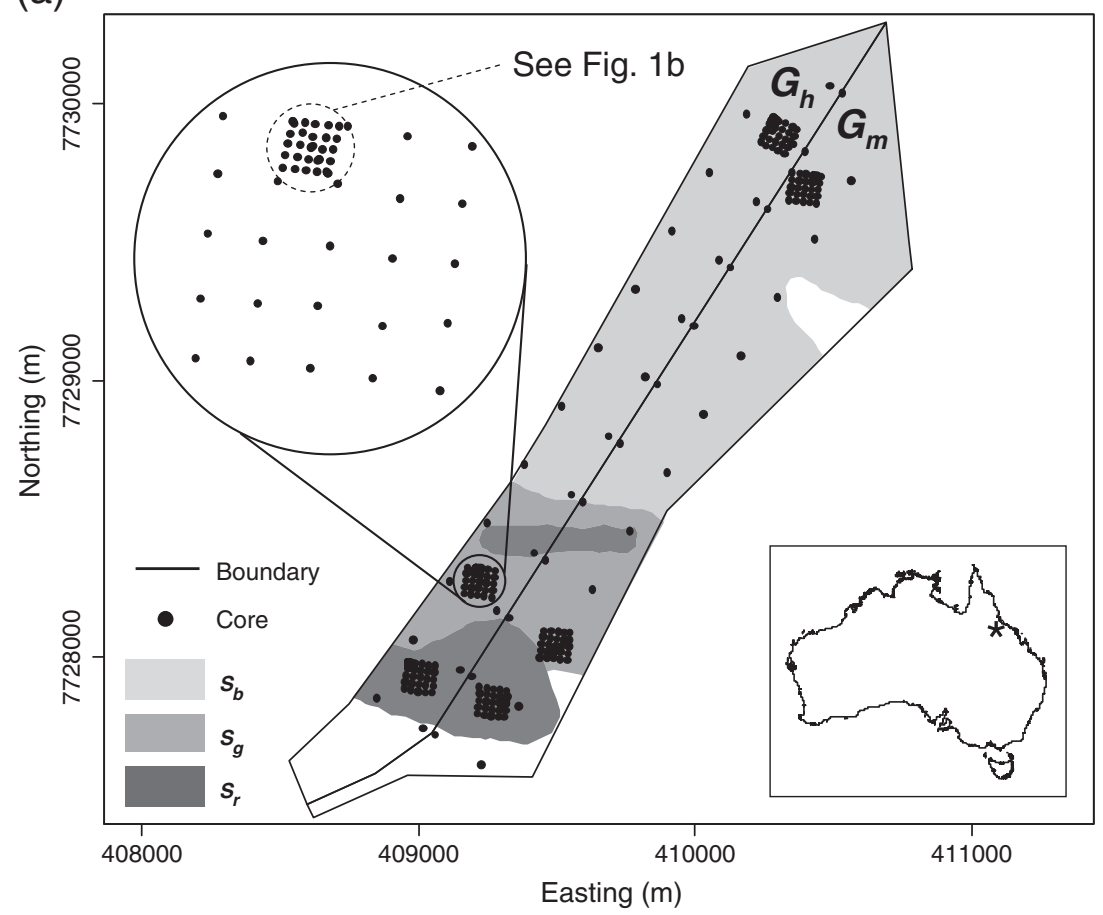

(b)

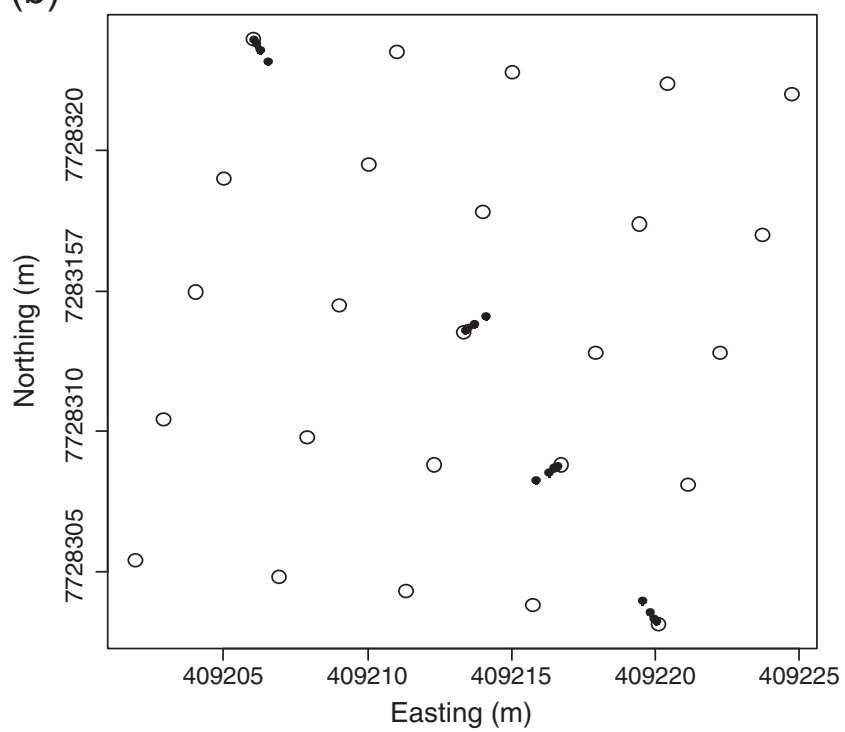

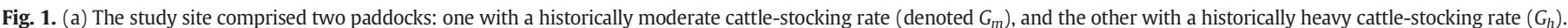

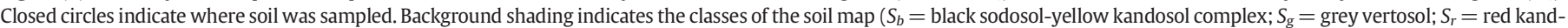

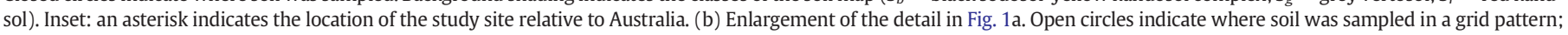
closed circles indicate where soil was sampled on exponentially spaced transects.

'material' coordinate system), rather than the more conventional depth (a 'spatial' coordinate system). To do this, we modelled the depth function of $\rho$ for the soil profile at each location with an equal-area quadratic smoothing spline (Bishop et al., 1999). The smoothing parameter of the spline, $\lambda$, was set at 0.0005 , which we determined by visual inspection. The spline was then used to predict $\rho$ at $0.02-\mathrm{m}$ increments within the profile to $0.5 \mathrm{~m}$. The cumulative soil mass (units of $\mathrm{Mg} \mathrm{ha}^{-1}$ ) to a particular depth, $d$, in the profile was computed as:

$M_{d}=\sum_{i=1}^{n}\left(\hat{\rho}_{i} \times 0.02 \times 10000\right)$, where $n$ was the number of $0.02-\mathrm{m}$ increments between the soil surface and $d$, inclusive, and $\hat{\rho}_{i}$ was the $i^{\text {th }}$ spline estimate of bulk density in the profile. The depths of interest were $d=(0.1 \mathrm{~m}, 0.3 \mathrm{~m}, 0.5 \mathrm{~m})$. At a particular depth the reference cumulative soil mass, $M_{d \text {, min }}$, was taken as the smallest value of $M_{d}$ found across all sampled locations.

The depth functions of $C$ (Eq. 11) and $\delta^{13} C$ were modelled at 0.02 $\mathrm{m}$ intervals, as for $\rho$. This ensured that all three variables were at the same scale when subjected to further analysis. Carbon stock $\left(C_{s}\right.$, units of $\mathrm{Mg} \mathrm{ha}^{-1}$ ) associated with a particular $M_{d, \min }$ was:

$C_{\mathrm{s}}=\sum_{i=1}^{n}\left(\hat{C}_{i} / 100 \times \hat{\rho}_{i} \times 0.02 \times 10000\right)$, 
where, in this case, $n$ was the number of 0.02 -m increments between the soil surface and the depth where $M_{d, \text { min }}$ was reached, and $\hat{C}_{i}$ was the $i^{\text {th }}$ spline estimate of $C$ in the profile. For $\delta^{13} C$ we averaged the spline predictions between the soil surface and the depth where $M_{d \text {, min }}$ was reached.

We inspected $C_{s}$ and $\delta^{13} C$ at each $M_{d \text {, min }}$ for departures from normality. Webster and Oliver (2001) suggested that when a variable's coefficient of skewness exceeds 1.0 a logarithmic transformation is usually appropriate, to stabilise variance. The back-transformed mean, $\bar{z}$, of a log-transformed variable is (Zhou and Gao, 1997):

$\bar{z}=\exp \left(\bar{z}_{\mathrm{t}}+\sigma_{\mathrm{t}}^{2} / 2\right)$

where $\bar{z}_{\mathrm{t}}$ and $\sigma_{\mathrm{t}}^{2}$ are the log-transformed mean and variance, respectively. We applied no transformation to variables with a coefficient of skewness $<1.0$.

\subsection{Linear mixed models of $C_{s}$ and $\delta^{13} C$}

Throughout this section we denote $C_{\mathrm{s}}$ and $\delta^{13} \mathrm{C}$ as, respectively, the length- $n_{1}$ vector $\mathbf{z}_{1}$ and the length- $n_{2}$ vector $\mathbf{z}_{2}$. As in Section $2, \mathbf{z}=$ $\left(\mathbf{z}_{1}^{T}, \mathbf{z}_{2}^{T}\right)^{T}$.

\subsubsection{Fitting the model}

At a particular $M_{d, \text { min }}$ the most complex LMM possible was $L_{1}$ (Table 2). For this model the design matrix, $\mathbf{X}$, had 12 columns, parameters $\beta_{0}-\beta_{5}$ related to $\mathbf{z}_{1}\left(C_{\mathrm{s}}\right)$, and parameters $\beta_{6}-\beta_{11}$ related to $\mathbf{z}_{2}\left(\delta^{13} C\right)$. We specified that the effective range for the LMCR of the random effects could not exceed $300 \mathrm{~m}$, approximately half the smallest dimension of the study area. We used a simplex algorithm (Nelder and Mead, 1965) to find the optimum parameter estimates for $L_{1}$. If the constraints on the LMCR were violated at a particular point in the simplex space we set $-l_{R}(\boldsymbol{\theta}, \mathbf{X}, \mathbf{S z}$ ) (Eq. (4)) to an arbitrary large number (much larger than the typical values of $-l_{R}(\boldsymbol{\theta}, \mathbf{X}$, Sz)), to place the algorithm on an alternative path to a valid minimum. This approach can create problems if the solution lies at the edge of the parameter space but, in our experience, we have found negligible difference to the outcome of other optimisation methods such as simulated annealing. To reduce the risk of obtaining a solution at a local minimum we fitted the LMM 200 times, with the initial values of $\theta$ randomly perturbed to within $25 \%$ of the original guesses. The LMM of the 200 candidates that returned the smallest value of $-l_{R}(\boldsymbol{\theta}, \mathbf{X}, \mathbf{S z})$ was then chosen for further analysis.

\subsubsection{Hypothesis testing}

We wanted to know if the components of $L_{1}$ that related to $\mathbf{z}_{1}$ (or $\mathbf{z}_{2}$ ) showed: (i) no effect for either grazing pressure or soil type; (ii) an effect of grazing pressure but not soil type; (iii) an effect of soil type but not grazing pressure; or, (iv) an interactive effect of both grazing

Table 2

The pool of linear mixed models needed for inference at $M_{d \text {, min }}$. Following the notation of Section 2, vector $\mathbf{z}$ is the concatenation of the observations of $C_{\mathrm{s}}$ and $\delta^{13} C$.

\begin{tabular}{lrl}
\hline Model & Form \\
\hline$L_{1}$ & $z_{i}=\beta_{0}+G_{m, i} \beta_{1}+S_{g, i} \beta_{2}+S_{r, i} \beta_{3}+G_{m, i} S_{g, i} \beta_{4}+G_{m, i} S_{r, i} \beta_{5}+$ \\
& $\beta_{6}+G_{m, i} \beta_{7}+S_{g, i} \beta_{8}+S_{r, i} \beta_{9}+G_{m, i} S_{g, i} \beta_{10}+G_{m, i} S_{r, i} \beta_{11}+u_{i}$ \\
$z_{2}$ & $\beta_{0}+S_{g, i} \beta_{1}+S_{r, i} \beta_{2}+$ \\
& $\beta_{3}+G_{m, i} \beta_{4}+S_{g, i} \beta_{5}+S_{r, i} \beta_{6}+G_{m, i} S_{g, i} \beta_{7}+G_{m, i} S_{r, i} \beta_{8}+u_{i}$ \\
$Z_{3}$ & $z_{i}=\beta_{0}+G_{m, i} \beta_{1}+S_{g, i} \beta_{2}+S_{r, i} \beta_{3}+G_{m, i} S_{g, i} \beta_{4}+G_{m, i} S_{r, i} \beta_{5}+$ \\
& $\beta_{6}+S_{g, i} \beta_{7}+S_{r, i} \beta_{8}+u_{i}$ \\
\hline
\end{tabular}

Key (following Eq. (2)): $z_{i}$ was the $i^{\text {th }}$ value of $z ; \beta$. were parameters that related particular combinations of grazing treatments and soil types to $z ; G_{m, i}$ was an indicator for the presence of moderate grazing; $S_{g, i}$ and $S_{r, i}$ were indicators for the presence of grey vertosol and red kandosol, respectively; and $u_{i}$ was the random effect. Heavy grazing $\left(G_{h, i}\right)$ and the brown sodosol-yellow kandosol complex $\left(S_{b, i}\right)$ were regarded implicitly as reference variables. pressure and soil type. Section 2.1 introduced how likelihood ratio tests can be used to compare nested LMMs. We could theoretically make 5 comparisons between pairs of nested models for each response variable in $L_{1}$. However, we suggest that a parsimonious form of the model can be established with just two carefully selected comparisons per response variable: we focussed initially on the effect of management and tested whether grazing affected $\mathbf{z}_{1}$ ( or $\mathbf{z}_{2}$ ); if it did, then we tested whether this effect was different for different soil types; otherwise, we tested whether soil type (in isolation) had an effect on $\mathbf{z}_{1}$ (or $\mathbf{z}_{2}$ ). Thus we were able to determine which of (i)-(iv) listed above appropriately described each response variable. More formally we established three null hypotheses for each response variable:

The expected value of $\mathbf{z}_{1}$ or $\mathbf{z}_{2}$ for all grazing treatments is equal.

If $(\mathrm{H} 1)$ is rejected then:

The expected value of $\mathbf{z}_{1}$ or $\mathbf{z}_{2}$ for

all soil types is equal for all grazing treatments.

If $(\mathrm{H} 1)$ is not rejected then:

The expected value of $\mathbf{z}_{1}$ or $\mathbf{z}_{2}$ for all soil types is equal.

The sequence of testing is illustrated in Fig. 2. Where a reduced model was fitted, the description in Section 2.1 was followed, with $-l_{R}\left(\boldsymbol{\theta}_{0}, \mathbf{X}_{0}\right.$, Sz) (Eq. (6)) minimised as described in Section 3.5.1, to determine whether $\boldsymbol{\beta}_{1}=\mathbf{0}$. Models $L_{2}$ and $L_{3}$ (Table 2 ) were fitted as for $L_{1}$, if required. For $L_{2}$, parameters $\beta_{0}-\beta_{2}$ related to $\mathbf{z}_{1}$, and parameters $\beta_{3}-\beta_{8}$ related to $\mathbf{z}_{2}$. For $L_{3}$, parameters $\beta_{0}-\beta_{5}$ related to $\mathbf{z}_{1}$, and parameters $\beta_{6}-\beta_{8}$ related to $\mathbf{z}_{2}$.

The outcome of the sequential testing allowed us to choose a parsimonious combination of fixed effects for a final LMM $\left(L_{f}\right)$ at each $M_{d \text {, min. }}$. Once fitted, $L_{f}$ was cross-validated according to the procedure described in Section 2.2. Pair-wise comparisons of individual soil types and grazing treatments (depending on what was present) were then done for $\mathbf{z}_{1}$ and $\mathbf{z}_{2}$ in turn, using the procedure described in Section 2.1.

\subsubsection{Decomposition of the random effects}

The structural correlation of two variables (Eq. (9) is a useful statistic, but a scatterplot allows a more immediate, visual interpretation. To this end, the random effects of $L_{f}$ can be decomposed into the contributions that correspond to the two nested scales of variation in the Matérn function (Eq. (1)). For example, the $i^{\text {th }}$ observation of $\mathbf{z}_{1}$ can actually be regarded as:

$z_{1, i}=\sum_{j=0}^{1} z_{1, i}^{q}$

where, as in Section 2, $q$ indexes spatial scale. We obtained the values of $z_{1, i}^{q}$ and $z_{2, i}^{q}$ using an EBLUP (Lark et al., 2006) analogue of factorial kriging (Goovaerts, 1997, p. 161):

$\mathbf{z}^{q}=\mathbf{V}^{q} \mathbf{V}^{-1}(\mathbf{z}-\mathbf{X} \boldsymbol{\beta})$

where $\mathbf{z}, \mathbf{X}, \boldsymbol{\beta}$, and $\mathbf{V}$ were defined in Section $2, \mathbf{z}^{q}$ was a length- $\left(n_{1}+n_{2}\right)$ vector comprising the values of $\mathbf{z}$ at the $q^{\text {th }}$ spatial scale, and $\mathbf{V}^{q}$ was analogous to $\mathbf{V}$, but its elements had been determined using only the parameters of $L_{f}$ associated with the $q^{\text {th }}$ structure of the Matérn function.

\subsection{Sampling for $C_{s}$}

The parameters of the random effects of $L_{f}$ were used to devise a design-based sampling scheme for $C_{\mathrm{s}}$ at a particular $M_{d \text {, min }}$. We established four hypothetical square-shaped polygons, denoted $W$, with areas 0.04 ha, 1 ha, 100 ha, and 2500 ha respectively. These polygons 


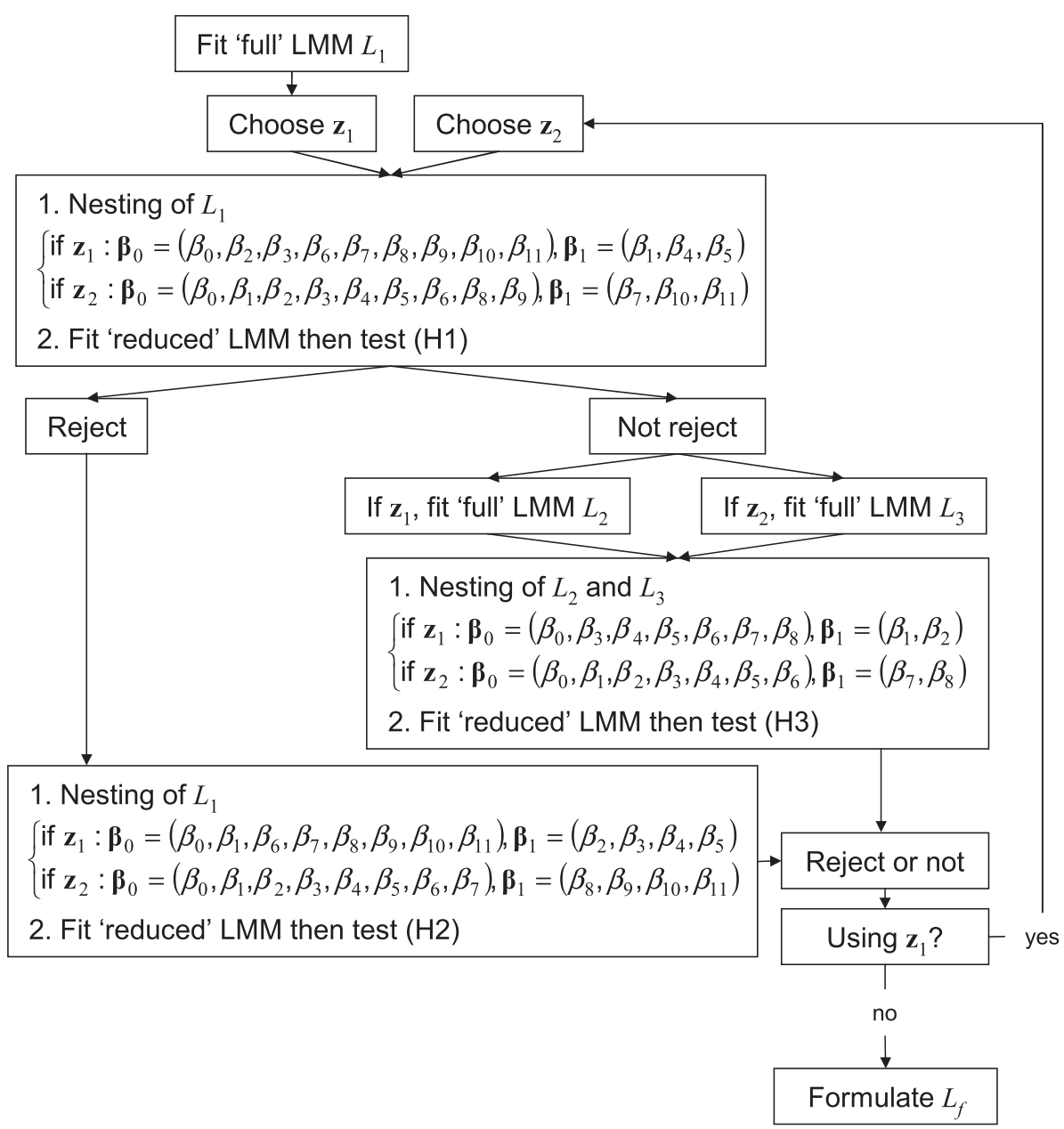

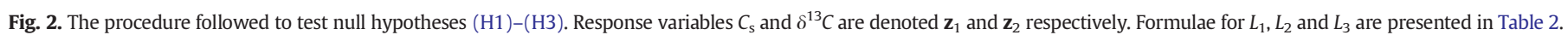

represented the extents expected for units of uniform soil type and grazing management in the tropical rangelands of Australia. Within each polygon we intended to sample $C_{s}$ at $n=(4,9,16,25,36,49,100)$ locations, where $n=100$ was taken as a pragmatic upper limit for feasibility. Bulking was not considered, i.e. each soil core was to be analysed separately. Samples were taken from three contrasting designs: simple random sampling (denoted SI), stratified simple random sampling (denoted ST), and systematic random sampling (denoted SY) (de Gruijter et al., 2006). Under SI all locations have equal probability of being allocated to a sample. Under ST the area is divided into a pre-specified number of sub-units ('strata'), then all locations within each stratum have equal probability of being allocated to a sample. Using the R statistical software (R Development Core Team, 2011), stratification was done on the basis of spatial coordinates, with a constraint that the strata have equal area (Walvoort et al., 2010). Design SY is a grid whose origin has been chosen at random.

Assuming that the variogram for a polygon is known, the modelbased estimation variance of the sample mean under SI is (Domburg et al., 1994):

$\sigma_{\mathrm{SI}}^{2}\left(\mu_{\mathrm{SI}}\right)=\frac{\bar{\gamma}(W, W)}{n}$

where $\mu_{\mathrm{SI}}$ represents the sample mean, and $\bar{\gamma}(W, W)$ is the dispersion variance (i.e. the expected variance of a single realisation of the random function of $C_{\mathrm{s}}$, defined by the parameters of $L_{f}$ ) across polygon $W$ (see Webster and Oliver, 2001, p. 151), computed from 1000 randomly generated pairs of locations within the polygon.
Under ST the estimation variance of the sample mean is (Domburg et al., 1994):

$\sigma_{\mathrm{ST}}^{2}\left(\mu_{\mathrm{ST}}\right)=\sum_{h=1}^{H}\left\{k_{h}^{2} / n_{h} \times \bar{\gamma}\left(W_{h}, W_{h}\right)\right\}$

where $\mu_{\mathrm{ST}}$ represents the sample mean, $H$ is the number strata, and, for the $h^{\text {th }}$ stratum: $k_{h}$ is the areal proportion of the stratum within $W ; n_{h}$ is the number of random samples (we used $n_{h}=2$ throughout); and, $\bar{\gamma}\left(W_{h}, W_{h}\right)$ is the dispersion variance, computed as for $\bar{\gamma}(W, W)$ above. The specification of $n_{h}=2$ meant that an even number of samples was required for the polygon overall, in which case we subtracted 1 from the odd-numbered instances of $n$, to thereby ensure a conservative estimate for $\sigma_{\mathrm{ST}}^{2}\left(\mu_{\mathrm{ST}}\right)$.

Under SY the estimation variance of the sample mean is (de Gruijter et al., 2006):

$\sigma_{\mathrm{SY}}^{2}\left(\mu_{\mathrm{SY}}\right)=\bar{\gamma}(W, W)-\bar{\gamma}(w, w)$

where $\mu_{S Y}$ represents the sample mean, and $\bar{\gamma}(w, w)$ is the dispersion variance of the $n$ locations in the grid. We actually computed $\sigma_{S Y}^{2}\left(\mu_{S Y}\right)$ as the mean of 20 grids with random origins and spacings that managed to fit $n$ locations into $W$. 


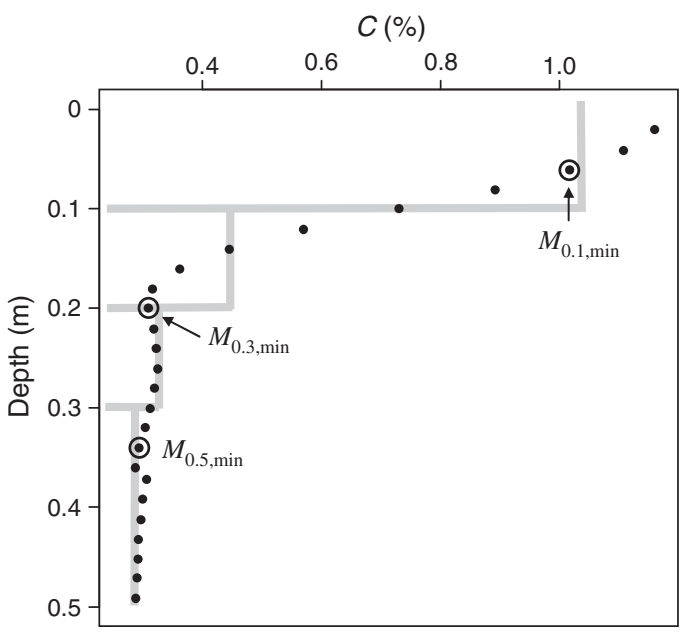

Fig. 3. Exemplary depth function. Grey lines indicate the observed concentrations of total organic carbon $(C)$, closed circles indicate the fitted values of the equal-area quadratic spline, and open circles indicate the depths where reference cumulative soil masses $\left(M_{d, \min }\right)$ were reached.

We converted the respective values of $\sigma_{\mathrm{SI}}^{2}\left(\mu_{\mathrm{SI}}\right), \sigma_{\mathrm{ST}}^{2}\left(\mu_{\mathrm{ST}}\right)$ and $\sigma_{\mathrm{SY}}^{2}\left(\mu_{\mathrm{SY}}\right)$ to Minimum Detectable Difference (MDD) (Zar, 1999):

$\operatorname{MDD}=\sqrt{\sigma_{i}^{2}\left(\mu_{i}\right)}\left(t_{0.025, n-1}+t_{0.8, n-1}\right)$,

where: $i=(\mathrm{SI}, \mathrm{ST}, \mathrm{SY})$; $t$ was Student's $t$ value; ' 0.025 ' indicated the confidence level for a two-sided test; $n-1$ was the degrees of freedom; and, '0.8' was the desired statistical power. MDD can be thought of as the smallest difference that can be detected between an observation and its 'true' value with the specified amount of confidence (Garten and Wullschleger, 1999).

\section{Results}

\subsection{Modelling of depth functions}

The three values of $M_{d, \min }$ used herein were found to be $M_{0.1, \min }=$ $977 \mathrm{Mg} \mathrm{ha}^{-1}, M_{0.3, \min }=3334 \mathrm{Mg} \mathrm{ha}^{-1}$, and $M_{0.5, \min }=5826 \mathrm{Mg} \mathrm{ha}^{-1}$. Fig. 3 presents, for one exemplary location, observed values of $C(\%)$ in the profile. The predictions of the spline function at $0.02-\mathrm{m}$ increments are also shown, as are the increments where each $M_{d, \text { min }}$ was reached. The location used for Fig. 3 had substantially heavier soil compared with the locations that defined the reference masses: the estimate of $C_{s}$ at $M_{0.1, \min }$ required application of Eq. (13) to $0.06 \mathrm{~m}$ depth only, while $C_{\mathrm{s}}$ at $M_{0.5 \text {, min }}$ was reached at $0.34 \mathrm{~m}$. The spline function of Bishop et al. (1999) required that there were no missing observations at any depth; otherwise the location had to be excluded from further analysis. From a maximum of 436 locations, there were 427 and 428 completely sampled locations for $C_{\mathrm{s}}$ and $\delta^{13} C$ respectively.

The histograms of $C_{s}$ at each $M_{d \text {, min }}$ showed strong positive skewness (not shown), suggesting that as the mean increased so too did the variance. Transformation of $C_{\mathrm{s}}$ to natural logarithms reduced the skew in each case. The histograms of transformed $C_{\mathrm{s}}$ did not suggest the presence of outliers (Fig. 4a). The histograms of $\delta^{13} C$ showed increasing negative skew as the cumulative soil mass increased (Fig. 4b), though not serious enough to justify transformation. (a) $C_{\mathrm{s}}\left(\ln \mathrm{Mg} \mathrm{ha}^{-1}\right)$

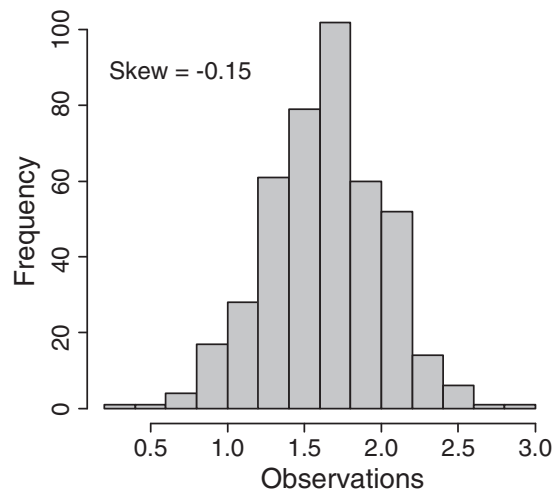

(b) $\delta^{13} C(\%)$

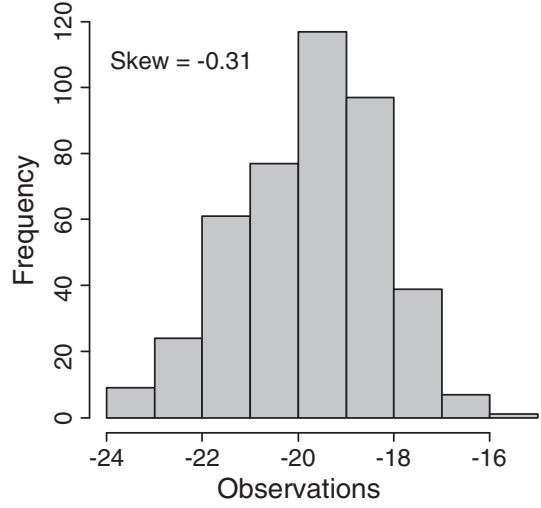

$M_{0.3, \min }$
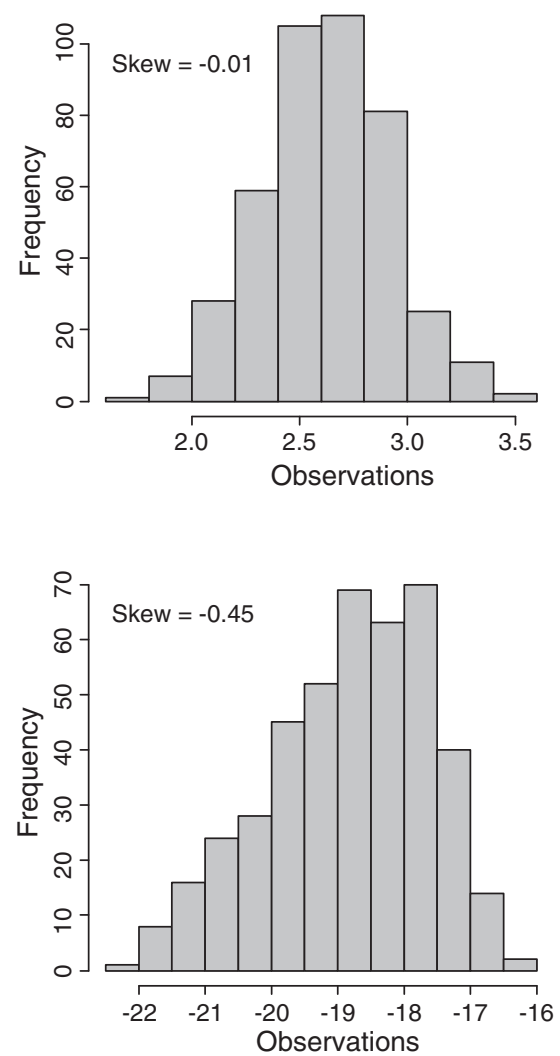

$M_{0.5, \min }$
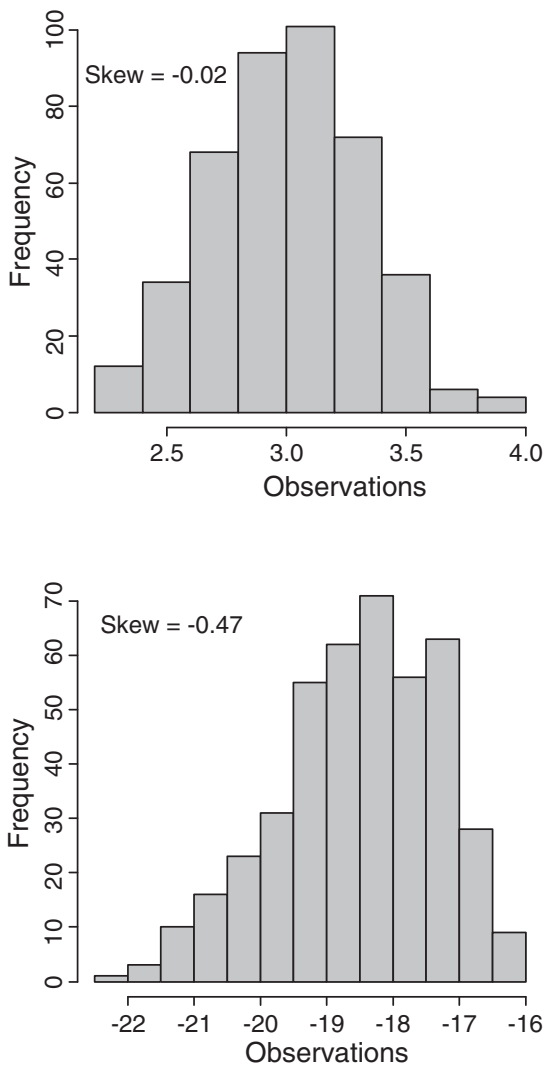

Fig. 4. Histograms of (a) log-transformed $C_{s}$, and (b) $\delta^{13} C$ for each reference cumulative soil mass $\left(M_{d, \min }\right)$. 
Table 3

The sequence of hypothesis tests for the fixed effects of the linear mixed models for $C_{\mathrm{s}}$ and $\delta^{13} \mathrm{C}$.

\begin{tabular}{|c|c|c|c|c|c|c|}
\hline Variable & 'Full' model & Test & $l_{R}(\boldsymbol{\theta}, \mathbf{X}, \mathbf{S z})$ & $l_{R}\left(\boldsymbol{\theta}_{0}, \mathbf{X}_{0}, \mathbf{S z}\right)$ & $g$ & $D$ \\
\hline \multicolumn{7}{|c|}{ (a) $M_{0.1, \min }$} \\
\hline \multirow[t]{2}{*}{$C_{\mathrm{s}}$} & $L_{1}$ & (H1) & -322.6 & -331.1 & 3 & $17.0^{* * * *}$ \\
\hline & $L_{1}$ & $(\mathrm{H} 2)$ & -322.6 & -343.2 & 4 & $41.2^{* * *}$ \\
\hline \multirow[t]{2}{*}{$\delta^{13} \mathrm{C}$} & $L_{1}$ & (H1) & -322.6 & -326.0 & 3 & 6.8 \\
\hline & $L_{3}$ & (H3) & -316.7 & -322.6 & 2 & $11.8^{* *}$ \\
\hline \multicolumn{7}{|c|}{ (b) $M_{0.3, \min }$} \\
\hline \multirow[t]{2}{*}{$C_{\mathrm{s}}$} & $L_{1}$ & (H1) & -312.3 & -316.9 & 3 & $9.3^{*}$ \\
\hline & $L_{1}$ & $(\mathrm{H} 2)$ & -312.3 & -330.1 & 4 & $35.6^{* * *}$ \\
\hline \multirow[t]{2}{*}{$\delta^{13} C$} & $L_{1}$ & (H1) & -312.3 & -314.7 & 3 & 4.9 \\
\hline & $L_{3}$ & (H3) & -304.5 & -313.6 & 2 & $18.2^{* * *}$ \\
\hline \multicolumn{7}{|c|}{ (c) $M_{0.5, \text { min }}$} \\
\hline \multirow[t]{2}{*}{$C_{\mathrm{s}}$} & $L_{1}$ & (H1) & -338.0 & -340.0 & 3 & 4.8 \\
\hline & $L_{2}$ & (H3) & -331.9 & -351.3 & 2 & $38.9^{* * *}$ \\
\hline \multirow[t]{2}{*}{$\delta^{13} C$} & $L_{1}$ & (H1) & -338.0 & -339.7 & 3 & 4.9 \\
\hline & $L_{3}$ & (H3) & -329.5 & -338.2 & 2 & $17.4^{* * *}$ \\
\hline
\end{tabular}

* Significant at $P=0.05$

** Significant at $P=0.01$.

*** Significant at $P=0.001$.

\subsection{Linear mixed modelling of $C_{s}$ and $\delta^{13} \mathrm{C}$}

The sequence of likelihood ratio tests (Table 3 ) indicated that, for $M_{0.1, \text { min }}$ and $M_{0.3, \text { min }}, C_{s}$ was influenced significantly by an interaction between grazing pressure and soil type, i.e. the full complement of fixed effects was justified in each case. At $M_{0.5 \text {, min }}$ however there was a significant effect of soil type on $C_{s}$ but no effect of grazing pressure. For $\delta^{13} C$ the tests indicated a strong effect of soil type at each of the three cumulative soil masses, but no effect of grazing pressure. The final, parsimonious LMMs for $C_{\mathrm{s}}$ and $\delta^{13} C$ at $M_{0.1, \text { min }}$ and $M_{0.3, \text { min }}$ took the form:

$$
\begin{aligned}
L_{f}= & \beta_{0}+G_{m, i} \beta_{1}+S_{g, i} \beta_{2}+S_{r, i} \beta_{3}+G_{m, i} S_{g, i} \beta_{4}+G_{m, i} S_{r, i} \beta_{5}+\beta_{6} \\
& +S_{g, i} \beta_{7}+S_{r, i} \beta_{8},
\end{aligned}
$$

where parameters $\beta_{0}-\beta_{5}$ related to $C_{\mathrm{s}}$, and parameters $\beta_{6}-\beta_{8}$ related to $\delta^{13} C$. At $M_{0.5, \text { min }}$ the final LMM was:

$L_{f}=\beta_{0}+S_{g, i} \beta_{1}+S_{r, i} \beta_{2}+\beta_{3}+S_{g, i} \beta_{4}+S_{r, i} \beta_{5}$,

where parameters $\beta_{0}-\beta_{2}$ related to $C_{\mathrm{s}}$, and parameters $\beta_{3}-\beta_{5}$ related to $\delta^{13} \mathrm{C}$.

We converted the fixed effects of $L_{f}$ at $M_{0.1, \min }, M_{0.3, \min }$, and $M_{0.5 \text {, min }}$ (Tables 4a, 5a and 6a, respectively) to fitted values for $C_{\mathrm{s}}$ and $\delta^{13} \mathrm{C}$ (Tables $4 \mathrm{~b}, 5 \mathrm{~b}$ and $6 \mathrm{~b}$, respectively). At all $M_{d, \mathrm{~min}}, C_{\mathrm{s}}$ for the red kandosol was significantly smaller than for the other two soil types, for both moderate and heavy grazing. At $M_{0.3, \text { min }}, C_{\mathrm{s}}$ of the brown sodosol-yellow kandosol complex and the grey vertosol was not significantly different when subjected to moderate grazing (Table $5 b$ ). At $M_{0.1, \text { min }}$ and $M_{0.3 \text {, min }}$ a change from moderate grazing to heavy grazing significantly decreased $C_{\mathrm{s}}$ for the grey vertosol and the red kandosol, but significantly increased $C_{\mathrm{s}}$ for the brown sodosol-yellow kandosol complex. At all three $M_{d, \text { min }}$ the brown sodosol-yellow kandosol complex had a significant depletion of $\delta^{13} \mathrm{C}$ compared with the other two soil types, i.e. the greatest $C_{3}$ contribution to soil organic carbon. The organic carbon contributions from $\mathrm{C}_{4}$ grasses were significantly greater for the red kandosol at $M_{0.3, \min }$ and $M_{0.5, \min }$ compared with the other two soil types.

The parameters of the random effects (Tables $4 c, 5 c, 6 c$ ) revealed four interesting insights. First, the effective range of the autocorrelated variation of $C_{\mathrm{s}}$ and $\delta^{13} \mathrm{C}$ was small relative to size of the study area ( $\sim 13 \mathrm{~m}$ on average). This result might not have been apparent if we had used a non-nested sampling design. Unfortunately it implies that the adjunct to the second aim of our study - i.e. mapping of $C_{\mathrm{s}}$ and $\delta^{13} \mathrm{C}$ at a within-paddock scale - is not practical because the required sampling effort would be too great. Second, $C_{s}$ and $\delta^{13} C$

Table 4

Values of the final linear mixed model fitted to $C_{\mathrm{s}}\left(\ln \mathrm{Mg} \mathrm{ha}^{-1}\right)$ and $\delta^{13} \mathrm{C}$ (\%) at $M_{0.1, \text { min }}$.

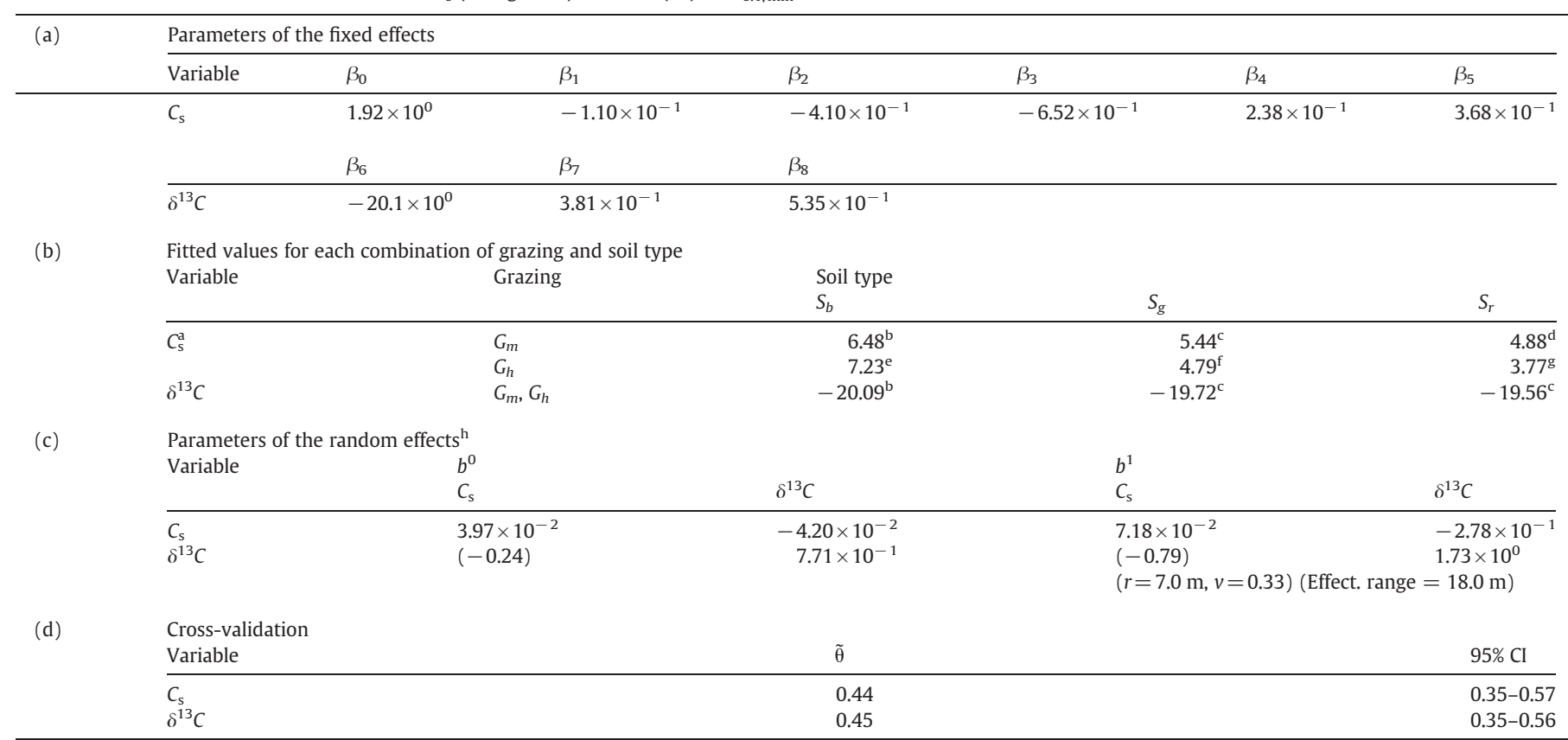

${ }^{\mathrm{a}} \mathrm{C}_{\mathrm{s}}$ has been back-transformed to $\mathrm{Mg} \mathrm{ha}^{-1}$ (Eq. (14)).

${ }^{\mathrm{b}-\mathrm{g}}$ Within variables, values with a common letter are not significantly different at $P=0.05$.

${ }^{\mathrm{h}}$ Structural correlations are in brackets in the lower triangle of each matrix. 
Table 5

Values of the final linear mixed model fitted to $C_{\mathrm{s}}\left(\ln \mathrm{Mg} \mathrm{ha}^{-1}\right)$ and $\delta^{13} C(\%)$ at $M_{0.3, \text { min }}$.

(a)

\begin{tabular}{lllll}
$\begin{array}{l}\text { Parameters of the fixed effects } \\
\text { Variable }\end{array}$ & $\beta_{0}$ & $\beta_{1}$ & $\beta_{2}$ & $\beta_{3}$ \\
\hline$C_{\mathrm{s}}$ & $2.81 \times 10^{0}$ & $-5.49 \times 10^{-2}$ & $-1.59 \times 10^{-1}$ & $-4.84 \times 10^{-1}$ \\
& $\beta_{6}$ & $\beta_{7}$ & $\beta_{8}$ & $\beta_{5}$ \\
\hline$\delta^{13} \mathrm{C}$ & $-19.4 \times 10^{0}$ & $4.38 \times 10^{-1}$ & $8.13 \times 10^{-1}$ &
\end{tabular}

(b) Fitted values for each combination of grazing and soil type

\begin{tabular}{|c|c|c|c|c|}
\hline Variable & Grazing & $\begin{array}{l}\text { Soil type } \\
S_{b}\end{array}$ & $S_{g}$ & $S_{r}$ \\
\hline \multirow[t]{2}{*}{$C_{\mathrm{s}}^{\mathrm{a}}$} & $G_{m}$ & $16.21^{\mathrm{b}}$ & $16.08^{b}$ & $11.40^{\circ}$ \\
\hline & $G_{h}$ & $17.13^{d}$ & $14.61^{\mathrm{e}}$ & $10.56^{\mathrm{f}}$ \\
\hline$\delta^{13} \mathrm{C}$ & $G_{m}, G_{h}$ & $-19.43^{b}$ & $-18.99^{c}$ & $-18.61^{\mathrm{c}}$ \\
\hline
\end{tabular}

(c) Parameters of the random effects ${ }^{g}$

\begin{tabular}{|c|c|c|c|c|}
\hline \multirow[t]{2}{*}{ Variable } & \multicolumn{2}{|l|}{$b^{0}$} & \multicolumn{2}{|l|}{$b^{1}$} \\
\hline & $C_{\mathrm{s}}$ & $\delta^{13} \mathrm{C}$ & $C_{\mathrm{s}}$ & $\delta^{13} C$ \\
\hline $\begin{array}{l}C_{\mathrm{s}} \\
\delta^{13} \mathrm{C}\end{array}$ & $\begin{array}{l}2.49 \times 10^{-2} \\
(-0.52)\end{array}$ & $\begin{array}{r}-6.47 \times 10^{-2} \\
6.12 \times 10^{-1}\end{array}$ & $\begin{array}{l}3.92 \times 10^{-2} \\
(-0.65) \\
(r=2.9 \mathrm{~m}, 1\end{array}$ & $\begin{array}{l}-1.18 \times 10^{-1} \\
8.50 \times 10^{-1} \\
=10.8 \mathrm{~m})\end{array}$ \\
\hline
\end{tabular}

(d)

\begin{tabular}{lll} 
Cross-validation & $\tilde{\theta}$ & $95 \%$ CI \\
Variable & 0.41 \\
\hline$C_{s}$ & 0.46 & $0.37-0.55$ \\
$\delta^{13} \mathrm{C}$ & $0.36-0.55$ \\
\hline
\end{tabular}

${ }^{\mathrm{a}} \mathrm{C}_{\mathrm{s}}$ has been back-transformed to $\mathrm{Mg} \mathrm{ha}^{-1}$ (Eq. (14)).

${ }^{\mathrm{b}-\mathrm{f}}$ Within variables, values with a common letter are not significantly different at $P=0.05$.

${ }^{\mathrm{g}}$ Structural correlations are in brackets in the lower triangle of each matrix.

showed the greatest magnitude of variation at $M_{0.1, \text { min }}$. Third, $C_{\mathrm{s}}$ and $\delta^{13} \mathrm{C}$ were correlated negatively (i.e. $C_{\mathrm{s}}$ decreased as $\delta^{13} \mathrm{C}$ tended to increase; in other words, the relative contribution of $C_{4}$ vegetation $C$ to $C_{\mathrm{s}}$ decreased). Fourth, the strength of the structural correlation

Table 6

Values of the final linear mixed model fitted to $C_{\mathrm{s}}\left(\ln \mathrm{Mg} \mathrm{ha}^{-1}\right)$ and $\delta^{13} \mathrm{C}(\%)$ at $M_{0.5 \text {, min. }}$.

\begin{tabular}{llll} 
(a) $\begin{array}{ll}\text { Parameters of the fixed effects } \\
\text { Variable }\end{array} \beta_{0}$ & $\beta_{1}$ & $\beta_{2}$ \\
\hline$C_{\mathrm{s}}$ & $3.13 \times 10^{0}$ & $-3.39 \times 10^{-2}$ & $-4.39 \times 10^{-1}$ \\
& $\beta_{3}$ & $\beta_{4}$ & $\beta_{5}$ \\
$\delta^{13} \mathrm{C}$ & $-19.0 \times 10^{0}$ & $5.70 \times 10^{-1}$ & $9.71 \times 10^{-1}$
\end{tabular}

(b) Fitted values for each combination of grazing and soil type

\begin{tabular}{|c|c|c|c|c|}
\hline Variable & Grazing & $\begin{array}{l}\text { Soil type } \\
S_{b}\end{array}$ & $S_{g}$ & $S_{r}$ \\
\hline$C_{\mathrm{s}}^{\mathrm{a}}$ & $G_{m}, G_{h}$ & $23.57^{b}$ & $24.38^{b}$ & $\overline{15.19^{c}}$ \\
\hline$\delta^{13} \mathrm{C}$ & $G_{m}, G_{h}$ & $-19.05^{b}$ & $-18.48^{c}$ & $-18.08^{d}$ \\
\hline
\end{tabular}

(c) Parameters of the random effects ${ }^{\mathrm{e}}$

\begin{tabular}{lllll} 
Variable & \multicolumn{1}{l}{$b^{0}$} & $b^{1}$ & \\
& $C_{\mathrm{s}}$ & $\delta^{13} \mathrm{C}$ & $C_{\mathrm{s}}$ & $\delta^{13} \mathrm{C}$ \\
\hline$C_{\mathrm{s}}$ & $2.90 \times 10^{-2}$ & $-6.58 \times 10^{-2}$ & $2.83 \times 10^{-2}$ & $-6.35 \times 10^{-1}$ \\
$\delta^{13} \mathrm{C}$ & $(-0.54)$ & $5.08 \times 10^{-1}$ & $(-0.43)$ & $7.61 \times 10^{-1}$ \\
& & & $(r=2.4 \mathrm{~m}, v=1.29)($ Effect. \\
& & & range $=10.8 \mathrm{~m})$
\end{tabular}

(d) Cross-validation

\begin{tabular}{lll} 
Variable & $\tilde{\theta}$ & $95 \% \mathrm{CI}$ \\
\hline$C_{\mathrm{s}}$ & 0.38 & $0.37-0.56$ \\
$\delta^{13} \mathrm{C}$ & 0.43 & $0.35-0.57$
\end{tabular}

${ }^{\mathrm{a}} C_{\mathrm{s}}$ has been back-transformed to $\mathrm{Mg} \mathrm{ha}^{-1}$ (Eq. 14).

${ }^{b-d}$ Within variables, values with a common letter are not significantly different at $P=0.05$.

${ }^{\text {e}}$ Structural correlations are in brackets in the lower triangle of each matrix.
(Eq. (9)) changed with depth and with spatial scale: as cumulative soil mass increased the negative correlation at the 'nugget' scale (i.e. distances $<0.1 \mathrm{~m}$ ) strengthened, but the negative correlation at the 'autocorrelated' scale (i.e. between $0.1 \mathrm{~m}$ and $\sim 13 \mathrm{~m}$ ) weakened. At $M_{0.1, \min }$, the correlation of $C_{\mathrm{s}}$ with $\delta^{13} \mathrm{C}$ at the autocorrelated scale was particularly strong (Fig. 5), which suggested that the broad spatial pattern of variation in $C_{s}$ was mirrored closely by $\delta^{13} C$. The sign of the correlation agrees with the findings of Powers (2006). A negative correlation reflects how the $\mathrm{C}_{4}$ grasses of the study site have contributed less $C$ to $C_{\mathrm{s}}$ than the $C_{3}$ trees and shrubs. This is expected since $C_{4}$ grasses would have been preferentially consumed by cattle,

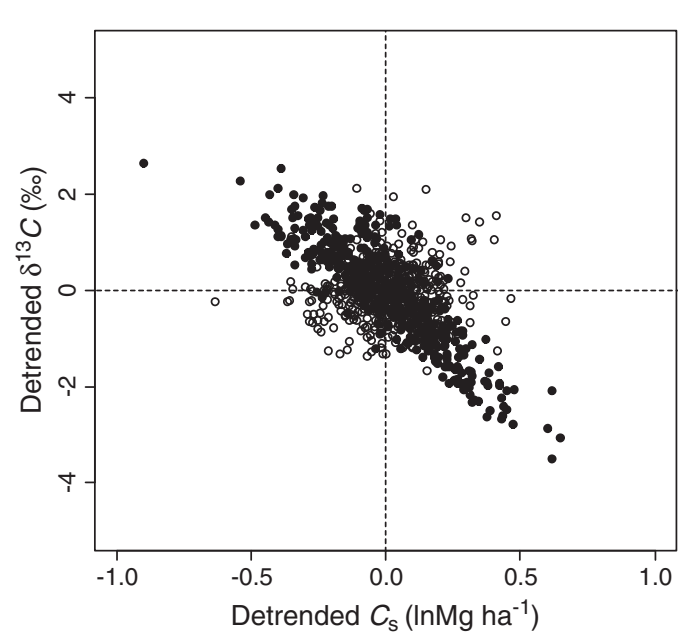

Fig. 5. The correlation of $C_{s}$ with $\delta^{13} C$ at $M_{0.1, \text { min }}$, decomposed into contributions from two spatial scales: (i) autocorrelated random variation (closed circles); and, (ii) independent random variation (open circles). Note that both variables have been detrended, as a result of the procedure for the linear mixed model. 
particularly during the dry years of 2001-2005. The implication for grazing management is that, while relatively more carbon might be sequestered into the soil when there is an increased density of woody species, forage production might decline due to competition from trees. Aside from reducing the potential to grow cattle, this could also lead to land degradation as the cattle place greater pressure on the remaining pasture. The $\tilde{\theta}$ statistics (Tables $4 d, 5 d, 6 d$ ) indicated that the assumption of multivariate-normal random effects was plausible at each $M_{d \text {, min }}$.

\subsection{Sampling for $C_{s}$}

Design-based sampling was the most appropriate option to explore. Had the spatial correlations (Tables $4 c, 5 c, 6 c$ ) continued over a longer range we could have estimated mean $C_{\mathrm{s}}$ by geostatistical methods. However for the observed spatial correlations this would have likely required thousands of observations, even if an optimised design (Marchant and Lark, 2006; McBratney and Webster, 1981; van Groenigen et al., 1999) had been used.

Table 7 presents the results for design-based sampling of $C_{\mathrm{s}}$ in grazed land, inferred through the LMM, assuming of course that the variogram parameters can be extrapolated at locations outside the study site. We have concentrated on sampling at $M_{0.1, \min }$ and $M_{0.3 \text {, min. }}$ These equate to nominal depth intervals of $0-0.1 \mathrm{~m}$ and $0-0.3 \mathrm{~m}$ in the soil profile; the former is expected to be the most responsive to changes in grazing management, while the latter is an internationally recognised standard for reporting of $C_{\mathrm{S}}$ (IPCC, 1996; p. 5.44). This table should be appraised with thresholds in mind that confer adequate detection of $C_{S}$. We used thresholds of $\pm 10 \%$ and $\pm 20 \%$ of the true mean of $C_{\mathrm{s}}$ (n.b. $\mathrm{Mg} \mathrm{ha}^{-1}$ ), which, when transformed, corresponded to $0.100 \ln \mathrm{Mg} \mathrm{ha}^{-1}$ and $0.203 \mathrm{ln} \mathrm{Mg} \mathrm{ha}^{-1}$, respectively. At $M_{0.3, \text { min }}$

\section{Table 7}

Minimum detectable difference (MDD) for $C_{\mathrm{s}}\left(\ln \mathrm{Mg} \mathrm{ha}^{-1}\right)$ at two cumulative soil masses, for simple (SI), stratified simple (ST), and systematic (SY) random sampling schemes.

\begin{tabular}{|c|c|c|c|c|c|c|c|}
\hline \multirow{2}{*}{$\begin{array}{l}W \\
\text { (ha) }\end{array}$} & \multirow[t]{2}{*}{$n$} & \multicolumn{3}{|c|}{ MDD at $M_{0.1, \min }$} & \multicolumn{3}{|c|}{ MDD at $M_{0.3, \min }$} \\
\hline & & SI & $\mathrm{ST}^{\mathrm{a}}$ & SY & SI & $\mathrm{ST}^{\mathrm{a}}$ & SY \\
\hline \multirow[t]{7}{*}{0.04} & 4 & 0.65 & 0.63 & 0.58 & 0.50 & 0.49 & 0.46 \\
\hline & 9 & 0.33 & 0.33 & 0.27 & 0.26 & 0.25 & 0.22 \\
\hline & 16 & 0.23 & 0.21 & 0.18 & 0.18 & 0.16 & 0.14 \\
\hline & 25 & 0.18 & 0.16 & 0.14 & 0.14 & 0.12 & 0.11 \\
\hline & 36 & 0.15 & 0.13 & 0.11 & 0.12 & 0.09 & 0.09 \\
\hline & 49 & 0.13 & 0.11 & 0.07 & 0.10 & 0.08 & 0.06 \\
\hline & 100 & 0.09 & 0.07 & 0.06 & 0.07 & 0.05 & 0.04 \\
\hline \multirow[t]{7}{*}{1} & 4 & 0.69 & 0.69 & 0.68 & 0.53 & 0.52 & 0.52 \\
\hline & 9 & 0.35 & 0.37 & 0.34 & 0.27 & 0.28 & 0.26 \\
\hline & 16 & 0.25 & 0.24 & 0.23 & 0.19 & 0.19 & 0.18 \\
\hline & 25 & 0.19 & 0.19 & 0.17 & 0.15 & 0.15 & 0.14 \\
\hline & 36 & 0.16 & 0.15 & 0.14 & 0.12 & 0.11 & 0.11 \\
\hline & 49 & 0.14 & 0.13 & 0.11 & 0.10 & 0.10 & 0.09 \\
\hline & 100 & 0.09 & 0.08 & 0.07 & 0.07 & 0.07 & 0.06 \\
\hline \multirow[t]{7}{*}{100} & 4 & 0.69 & 0.69 & 0.69 & 0.53 & 0.53 & 0.53 \\
\hline & 9 & 0.36 & 0.38 & 0.35 & 0.27 & 0.29 & 0.27 \\
\hline & 16 & 0.25 & 0.25 & 0.25 & 0.19 & 0.19 & 0.19 \\
\hline & 25 & 0.19 & 0.20 & 0.19 & 0.15 & 0.15 & 0.15 \\
\hline & 36 & 0.16 & 0.16 & 0.16 & 0.12 & 0.12 & 0.12 \\
\hline & 49 & 0.14 & 0.14 & 0.13 & 0.10 & 0.10 & 0.10 \\
\hline & 100 & 0.09 & 0.09 & 0.09 & 0.07 & 0.07 & 0.07 \\
\hline \multirow[t]{7}{*}{2500} & 4 & 0.69 & 0.69 & 0.69 & 0.53 & 0.53 & 0.53 \\
\hline & 9 & 0.36 & 0.38 & 0.35 & 0.27 & 0.29 & 0.27 \\
\hline & 16 & 0.25 & 0.25 & 0.25 & 0.19 & 0.19 & 0.19 \\
\hline & 25 & 0.19 & 0.20 & 0.19 & 0.15 & 0.15 & 0.15 \\
\hline & 36 & 0.16 & 0.16 & 0.16 & 0.12 & 0.12 & 0.12 \\
\hline & 49 & 0.14 & 0.14 & 0.13 & 0.10 & 0.10 & 0.10 \\
\hline & 100 & 0.09 & 0.09 & 0.09 & 0.07 & 0.07 & 0.07 \\
\hline
\end{tabular}

a MDD for ST was computed with $n-1$ when $n$ was an odd number.

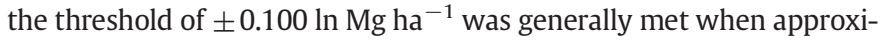
mately 50 samples were collected per unit. Accepting a larger threshold of $\pm 0.203 \mathrm{ln} \mathrm{Mg} \mathrm{ha}^{-1}$ (i.e. intentionally reducing the accuracy with which mean $C_{\mathrm{s}}$ can be characterised) greatly reduced the sampling effort, generally to between 9 and 16 samples. At a nominal depth interval of $0-0.1 \mathrm{~m}$, the sampling requirement slightly increased in all cases due to the increased variability of $C_{\mathrm{s}}$.

It can be seen in Table 7 that systematic random sampling (SY) was a more statistically efficient procedure than stratified simple random sampling (ST), which was itself more efficient than simple random sampling (SI). The difference between the three designs was less pronounced as the area of interest increased. We recommend ST (with equal-area geographic strata) as the most viable option for baseline sampling of $C_{\mathrm{s}}$. Design SI can be deferred on the basis of inefficiency. Design SY, while more efficient than ST when construed through model-based analysis, is not suitable for design-based inference because the user will ultimately have to rely on an approximation to the estimation variance; no exact design-based expression exists. The user might instead compute the design-based estimation variance as if the samples had been collected under SI, which will overestimate the true value and therefore lead to conservative inference (de Gruijter et al., 2006). The argument for ST is that, while moderately efficient, the user will know the estimation variance exactly, which is ultimately the key quantity for detecting a change in $C_{\mathrm{s}}$ through time (Dick Brus, pers. comm.).

\section{Discussion}

We contend that a more complete understanding of belowground carbon dynamics in a cattle-grazing system will be attained by measuring the soil simultaneously for $C_{\mathrm{s}}$ and $\delta^{13} \mathrm{C}$. At a coarse spatial scale, we have shown how soil type and 12 years' of continuous grazing pressure influence the mean of $C_{\mathrm{s}}$, and how soil type influences the mean of $\delta^{13} \mathrm{C}$. The null result for the effect of grazing on mean $\delta^{13} \mathrm{C}$ suggests that 12 years might be too short a period to see a definitive coarse-scale effect (Krull and Bray, 2005; Krull et al., 2005), although the drought of 2001-2005 might also have influenced this result through its effect on biomass production. Our finding that, at the spatial scale of autocorrelated variation, $C_{\mathrm{s}}$ might increase to the detriment of forage production has self-evident implications for grazing management. Each of these results was only apparent because linear mixed models were able to separate the 'fixed' effects of grazing and soil type from other 'random' sources of variation (Section 2).

The soil type effect on $C_{\mathrm{s}}$ can be explained by textural differences. The red kandosol, which has a relatively coarse texture (Ben Harms, pers. comm.), recorded the smallest $C_{\mathrm{s}}$, while the finer-textured vertosol and sodosol were associated with larger $C_{\mathrm{s}}$ (Tables $4 \mathrm{~b}, 5 \mathrm{~b}, 6 \mathrm{~b}$ ). Generally, fine-textured soil stores more plant-available water, retains more nutrients, and provides better soil structure for plant growth, and consequently, has more plant- $C$ input than coarse-textured soil. For the vertosol and sodosol it is likely that the relative abundance of deeper-rooted $C_{3}$ vegetation, as shown by the depletion of $\delta^{13} \mathrm{C}$ (Tables $4 \mathrm{~b}, 5 \mathrm{~b}, 6 \mathrm{~b}$ ), utilised water and nutrients more efficiently for biomass production than the red kandosol. Moreover, soil organic $\mathrm{C}$ in a coarse-textured soil has a faster decomposition rate, because it lacks the protection generally afforded by an abundance of clay particles (Chan et al., 2010; Hassink, 1997). We speculate that, to a nominal depth of $0.3 \mathrm{~m}$, the complexity of the soil-grazing interactions (Tables $4 \mathrm{~b}$ and $5 \mathrm{~b}$ ) relates to the increased prevalence of (generally unpalatable) native shrub Carissa ovata, at the expense of $\mathrm{C}_{4}$ grasses. Although ground-based observations show an increase in Carissa cover over the entire site in the last decade, this increase has been by far the largest on the brown sodosol-yellow kandosol complex, where its cover now exceeds $>25 \%$ in many parts. This could explain the increase in $C_{\mathrm{s}}$ seen for this soil type under heavy grazing. In 
contrast, the increase of Carissa ovata on the red kandosol has been far smaller (Peter O'Reagain, unpublished data).

Three key implications of our study relate to practical sampling issues for $C_{\mathrm{s}}$ in the rangelands of tropical Queensland. The first is that baseline sampling for $C_{\mathrm{s}}$ should be done to a cumulative soil mass of $3334 \mathrm{Mg} \mathrm{ha}^{-1}$ (i.e. a nominal depth interval of $0-0.3 \mathrm{~m}$ ) in the profile. Inclusion of soil from beyond this mass will smooth the baseline $C_{\mathrm{s}}$ signal such that, in the future, it may be difficult to show if there has been a significant change in $C_{\mathrm{s}}$ due to grazing management, the effects of which would concentrate at the top of the profile. The second key implication is that the interaction between soil type and grazing pressure creates a difficulty for efficient baseline sampling of $C_{s}$. Prior to collecting the baseline samples a soil surveyor will need to know where the classes of a soil map intersect with paddock boundaries. According to Table 7, the surveyor should look to place an adequate number of samples in every unit of the resulting intersection, but unfortunately few grazing properties in the Australian rangelands have a soil map as detailed as the trial site at Wambiana station. This lack of detail will lead to under-sampling of the landscape, which will increase the estimation variance and ultimately make it harder to detect a temporal change in $C_{s}$ due to grazing management. There is obviously an urgent need for improved pedological mapping at a spatial scale relevant to the graziers of the Australian rangelands. A high-throughput analytical method like diffuse reflectance spectroscopy of the soil cores (Viscarra Rossel et al., 2006) could be used as part of the sampling campaign, with the aim of improving the soil classification in an area. Furthermore, our results suggest that some sampling efficiencies can be made: for example, at a nominal depth interval of $0-0.3 \mathrm{~m}$ in the profile, $C_{\mathrm{s}}$ for the brown sodosol-yellow kandosol complex and the grey vertosol are equivalent under moderate grazing (Table $5 b$ ), and so they might be aggregated into a single sampling unit. The third key implication for sampling is that, in general, 25 samples in a landscape unit should be sufficient to characterise mean $C_{\mathrm{s}}$ (to within $20 \%$ of the true value) for nominal depth intervals of $0-0.1 \mathrm{~m}$ and $0-0.3 \mathrm{~m}$. It is arguable that the 'grey area' of $20 \%$ is too large for a viable carbon-monitoring scheme but a smaller target, say $10 \%$ of the true mean, entails a sampling effort that is likely to be prohibitive. We recommend the use of stratified simple random sampling, with strata of equal area defined by geographic coordinates (Walvoort et al., 2010), and at least two samples collected per strata.

We reiterate that the depth intervals we have cited throughout are only nominal: the results relate strictly to soil mass in the profile, which Gifford and Roderick (2003) and McBratney and Minasny (2010) recommended for reporting of $C_{s}$. But while Gifford and Roderick (2003) recommended $4000 \mathrm{Mg} \mathrm{ha}^{-1}$ as a rule-of-thumb for the $0-0.3 \mathrm{~m}$ interval - the internationally recognised standard for reporting of $C_{\mathrm{S}}$ (IPCC, 1996; p. 5.44) - we instead derived reference values that were specific to our own dataset. By using these references we ensured that the equal-area quadratic smoothing spline (Section 3.4) was only ever used to interpolate observed data, never for extrapolation. A disadvantage of the spline of Bishop et al. (1999) is that the soil layers sampled must be adjacent, with no intermediate layers missing. Fortunately, this requirement did not adversely influence our study, with only about $2 \%$ of the sampled locations were found to be unusable. Malone et al. (2009) presented a generalised spline that can deal with non-adjacent layers, which should be used in the future. An obvious complication is that bulk density will be unknown at the time of sampling, and so the investigator will not know how far to drill the soil core. As a solution Gifford and Roderick (2003) recommend drilling $0.1 \mathrm{~m}$ beyond the nominal depth required; practically, this implies that soil cores at Wambiana station should be drilled to $0.4 \mathrm{~m}$ depth to ensure that a soil mass of $3334 \mathrm{Mg} \mathrm{ha}^{-1}$ is attained.

With a view to improving future analyses we acknowledge four limitations of our study. First, due to the sampling design, our results draw on, in strict terms, an unreplicated treatment comparison. In hindsight it would have been more statistically efficient to spread the 436 samples over both replicates of each treatment, using, for example, a series of exponentially spaced transects to capture the spatial variability (Pettitt and McBratney, 1993). Second, we have assumed that the covariance of $C_{\mathrm{s}}$ with $\delta^{13} \mathrm{C}$ is constant across the study region. This might not be plausible: for example, Wiesmeier et al. (2009) demonstrated how grazing homogenises bulk density and the organic carbon concentration, reducing their spatial variability compared with ungrazed areas. A non-stationary LMM (Marchant et al., 2009) would allow us to investigate whether the assumption of constant variance is justified. Third, while we found no effect of grazing pressure on the mean of $\delta^{13} \mathrm{C}$ for total organic carbon, it might be possible to enhance the sensitivity by size-fractioning the $C$ prior to isotopic analysis. Krull et al. (2005) and Krull and Bray (2005) have shown, for two separate sites in the rangelands of tropical Queensland, how $\delta^{13} \mathrm{C}$ for particulate organic carbon ( $>53 \mu \mathrm{m}$ and $<200 \mu \mathrm{m}$ ) and for the $<53 \mu \mathrm{m}$ fraction of organic carbon vary substantially from that of total organic carbon, and how these differences can be related to historical vegetation management. Finally, the locational and measurement errors inherent in observing bulk density, organic carbon concentration, and $\delta^{13} \mathrm{C}$ are an inevitable source of uncertainty. If we could reduce the magnitude of these errors then we would be able to detect even smaller soil type and grazing effects.

\section{Conclusions}

For a long-term cattle-grazing trial in the tropical rangelands of Australia, we have used linear mixed models to elucidate: (i) the effect of soil type (delineated by pedological survey) and grazing pressure (sustained over a 12-year period) on soil carbon stock $\left(C_{\mathrm{s}}\right)$ and the stable carbon isotope ratio of soil organic carbon $\left(\delta^{13} C\right)$; (ii) the spatial covariation of $C_{\mathrm{s}}$ and $\delta^{13} C$; and, (iii) an optimal sampling scheme for $C_{s}$. The linear mixed models revealed that soil type and grazing pressure interacted to influence $C_{s}$ to a nominal depth of $0.3 \mathrm{~m}$ in the soil profile; the effect of grazing on $C_{\mathrm{s}}$ was not seen at a nominal depth of $0.5 \mathrm{~m}$, but the soil type effect on $C_{\mathrm{s}}$ at this depth was significant. Soil type influenced $\delta^{13} \mathrm{C}$ to a nominal depth of $0.5 \mathrm{~m}$ but there was no effect of grazing on $\delta^{13} \mathrm{C}$ at any depth in the profile to $0.5 \mathrm{~m}$. Linear mixed models showed the strong negative correlation of $C_{\mathrm{s}}$ with $\delta^{13} \mathrm{C}$, particularly at a nominal depth of $0.1 \mathrm{~m}$ in the soil profile. This suggested that the $C_{4}$ grasses of the study site contributed less to soil carbon than the $C_{3}$ trees and shrubs, presumably because the $C_{4}$ vegetation is preferentially consumed by the animals. One inference is that $C_{\mathrm{s}}$ may increase at the expense of forage availability, reducing carrying capacity. Our sampling recommendation for grazing properties of the tropical rangelands of Australia is to: (i) divide the property into units of apparently uniform soil type and grazing management; (ii) use stratified simple random sampling to spread at least 25 soil sampling locations about each unit, with at least two samples collected per stratum.

\section{Acknowledgements}

We thank Meat and Livestock Australia, the Department of Environment and Resource Management (DERM), and the Department of Employment, Economic Development and Innovation (DEEDI) for funding this study. BPM's contribution was conducted under Rothamsted Research's programme in Computational and Mathematical Biology, which is funded by the Biotechnology and Biological Sciences Research Council of the United Kingdom. We thank Steven Bray, Grant Fraser, Angelique Woods, and lain Gibson for assistance with fieldwork and sample processing, Rene Diocares for the total $C$ and ${ }^{13} \mathrm{C}$ analyses, Ben Harms for the soil information in Table 1, and Dick Brus for the insights on sampling. 


\section{References}

Allen, D.E., Pringle, M.J., Page, K.L., Dalal, R.C., 2010. A review of sampling designs for the measurement of soil organic carbon in Australian grazing lands. The Rangeland Journal 32, 227-246.

Bagchi, S., Ritchie, M.E., 2010. Introduced grazers can restrict potential soil carbon sequestration through impacts on plant community composition. Ecology Letters 13, 959-968.

Bishop, T.F.A., McBratney, A.B., Laslett, G.M., 1999. Modelling soil attribute depth functions with equal-area quadratic smoothing splines. Geoderma 91, 27-45.

Boutton, T.W., Archer, S.R., Midwood, A.J., Zitzer, S.F., Bol, R., 1998. $\delta^{13} \mathrm{C}$ values of soil organic carbon and their use in documenting vegetation change in a subtropical savanna ecosystem. Geoderma $82,5-41$.

Bray, S.G., Krull, E.S., Harms, B.P., Baxter, N., Rutherford, M., Yee, M., Cogle, L., 2006. Assessment of vegetation change in the Burdekin Catchment of Queensland. Project Report Q106091. Department of Primary Industries and Fisheries, Brisbane.

Chan, K.Y. Oates, A., Li, G.D. Conyers, M.K., Prangnell, R.J., Poile, G., Liu, D.L., Barchia, I.M. 2010. Soil carbon stocks under different pastures and pasture management in the higher rainfall areas of south-eastern Australia. Australian Journal of Soil Research 48, 7-15.

Craig, H., 1953. The geochemistry of the stable carbon isotopes. Geochimica et Cosmochimica Acta 3, 53-92.

de Gruijter, J.J., Brus, D.J., Bierkens, M.F.P., Knotters, M., 2006. Sampling for Natural Resource Monitoring. Springer, Berlin.

Derner, J.D., Schuman, G.E., 2007. Carbon sequestration and rangelands: A synthesis of land management and precipitation effects. Journal of Soil and Water Conservation $62,77-85$.

Domburg, P., de Gruijter, J.J., Brus, D.J., 1994. A structured approach to designing soil survey schemes with prediction of sampling error from variograms. Geoderma 62, 151-164.

Ehleringer, J.R., Buchmann, N., Flanagan, L.B., 2000. Carbon isotope ratios in belowground carbon cycle processes. Ecological Applications 10, 412-422.

Fernandes, M., Krull, E., 2008. How does acid treatment to remove carbonates affect the isotopic and elemental composition of soils and sediments? Environmental Chemistry 5 33-39.

Follett, R.F., Reed, D.A., 2010. Soil carbon sequestration in grazed lands: Societal benefits and policy implications. Rangeland Ecology and Management 63, 4-15.

Garten, C.T., Wullschleger, S.D., 1999. Soil carbon inventories under a bioenergy crop (Switchgrass): Measurement limitations. Journal of Environmental Quality 28 1359-1365.

Gifford, R.M., Roderick, M.L., 2003. Soil carbon stocks and bulk density: spatial or cumulative mass coordinates as a basis of expression? Global Change Biology 9, 1507-1514.

Goovaerts, P., 1997. Geostatistics for Natural Resource Evaluation. Oxford University Press, New York.

Gunn, R.H., Beattie, J.A., Reid, R.E., van de Graff, R.H.M., 1988. Australian Soil and Land Survey Handbook: Guidelines for Conducting Surveys. Inkata Press, Melbourne.

Hassink, J., 1997. The capacity of soils to preserve organic $\mathrm{C}$ and $\mathrm{N}$ by their association with clay and silt particles. Plant and Soil 191, 77-87.

IPCC, 1996. Land-use change and forestry. Revised 1996 Guidelines for National Greenhouse Gas Inventories: Reference Manual. Intergovernmental Panel for Climate Change http://www.ipcc-nggip.iges.or.jp/public/gl/invs6d.html. Accessed: 21/07/2011.

Isbell, R.F., 2002. The Australian Soil Classification, revised ed. CSIRO Publishing Melbourne.

IUSS Working Group WRB, 2007. World reference base for soil resources 2006. At World Soil Resources Reports No. 103. FAO, Rome ftp://ftp.fao.org/agl/agll/docs/ wsrr103e.pdf. Accessed: 21/07/2011.

Krull, E.G., Bray, S.S., 2005. Assessment of vegetation change and landscape variability by using stable carbon isotopes of soil organic matter. Australian Journal of Botany 53, 651-661.

Krull, E.S., Skjemstad, J.O., Burrows, W.H., Bray, S.G., Wynn, J.G., Bol, R., Spouncer, L., Harms, B., 2005. Recent vegetation changes in central Queensland, Australia: Evidence from $\delta{ }^{13} \mathrm{C}$ and ${ }^{14} \mathrm{C}$ analyses of soil organic matter. Geoderma 126, 241-259.

Lark, R.M., 2000. A comparison of some robust estimators of the variogram for use in soil survey. European Journal of Soil Science 51, 137-157.

Lark, R.M., Cullis, B.R., 2004. Model-based analysis using REML for inference from systematically sampled data on soil. European Journal of Soil Science 55, 799-813.

Lark, R.M., Cullis, B.R., Welham, S.J., 2006. On spatial prediction of soil properties in the presence of a spatial trend: the empirical best linear unbiased predictor (E-BLUP) with REML. European Journal of Soil Science 57, 787-799.

Linn, D.M., Doran, J.W., 1984. Effect of water-filled pore space on carbon dioxide and nitrous oxide production in tilled and nontilled soils. Soil Science Society of America Journal 48, 1267-1272.

Malone, B.P., McBratney, A.B., Minasny, B., Laslett, G.M., 2009. Mapping continuous depth functions of soil carbon storage and available water capacity. Geoderma $154,138-152$.

Marchant, B.P., Lark, R.M., 2006. Adaptive sampling and reconnaissance surveys for geostatistical mapping of the soil. European Journal of Soil Science 57, 831-845.

Marchant, B.P., Lark, R.M., 2007. Estimation of linear models of coregionalization by residual maximum likelihood. European Journal of Soil Science 58, 1506-1513.

Marchant, B.P., Newman, S., Corstanje, R., Reddy, K.R., Osborne, T.Z., Lark, R.M., 2009 Spatial monitoring of a non-stationary soil property: phosphorus in a Florida water conservation area. European Journal of Soil Science 60, 757-769.
Matheron, G., 1963. Principles of geostatistics. Economic Geology 58, 1246-1266.

McBratney, A.B., Minasny, B., 2010. Comment on "Determining soil carbon stock changes: Simple bulk density corrections fail" [Agric. Ecosyst. Environ. 134 (2009) 251-256]. Agriculture, Ecosystems \& Environment 136, 185-186.

McBratney, A.B., Webster, R., 1981. The design of optimal sampling schemes for local estimation and mapping of regionalized variables: II. Program and examples. Computers and Geosciences 7, 335-365.

Minasny, B., McBratney, A.B., 2005. The Matérn function as a general model for soil variograms. Geoderma 128, 192-207.

Nelder, J.A., Mead, R., 1965. A simplex method for function minimization. The Computer Journal 7, 308-313.

O'Reagain, P., Bushell, J., 1999. Testing grazing strategies for the seasonably variable tropical savannas. In: Eldridge, D., Freudenberger, D. (Eds.), People and Rangelands, Building the Future: Proceedings of the VI International Rangeland Congress. VI International Rangeland Congress, Inc., Aitkenvale, pp. 485-486.

O'Reagain, P., Bushell, J., Holloway, C., Reid, A., 2009. Managing for rainfall variability: effect of grazing strategy on cattle production in a dry tropical savanna. Animal Product Science 49, 85-99.

O'Reagain, P., Bushell, J., Holmes, B., 2011. Managing for rainfall variability: long-term profitability of different grazing strategies in a northern Australian tropical savanna. Animal Product Science 51, 210-224.

Patterson, H.D., Thompson, R., 1971. Recovery of inter-block information when block sizes are unequal. Biometrika 58, 545-554.

Peterson, B.J., Fry, B., 1987. Stable isotopes in ecosystem studies. Annual Review of Ecology and Systematics 18, 293-320.

Pettitt, A.N., McBratney, A.B., 1993. Sampling designs for estimating spatial variance components. Journal of the Royal Statistical Society Series C: Applied Statistics 42, 185-209.

Piñeiro, G., Paruelo, J.M., Oesterheld, M., Jobbágy, E.G., 2010. Pathways of grazing effects on soil organic carbon and nitrogen. Rangeland Ecology and Management $63,109-119$

Powers, J.S., 2006. Spatial variation of soil organic carbon concentrations and stable isotopic composition in 1-ha plots of forest and pasture in Costa Rica: implications for natural abundance technique. Biology and Fertility of Soils 42, 580-584.

Pringle, M.J., Baxter, S.J., Marchant, B.P., Lark, R.M., 2008a. Spatial analysis of the error in a model of soil nitrogen. Ecological Modelling 211, 453-467.

Pringle, M.J., Marchant, B.P., Lark, R.M., 2008b. Analysis of two variants of a spatially distributed crop model, using wavelet transforms and geostatistics. Agricultural Systems 98, 135-146.

R Development Core Team, 2011. R: A Language and Environment for Statistical Computing. At R Foundation for Statistical Computing, Vienna, Austria. http://www.rproject.org. Accessed 21/07/2011.

Rayment, G.E., Higginson, F.R., 1992. Australian Laboratory Handbook of Soil and Water Chemical Methods. Inkata Press, Melbourne.

Rogers, L.G., Cannon, M.G., Barry, E.V., 1999. Land Resources of the Dalrymple Shire. Department of Natural Resources, Brisbane.

Rossi, J., Govaerts, A., De Vos, B., Verbist, B., Vervoort, A., Poesen, J., Muys, B., Deckers, J., 2009. Spatial structures of soil organic carbon in tropical forests-A case study of Southeastern Tanzania. Catena 77, 19-27.

Schöning, I., Totsche, K.U., Kögel-Knabner, I., 2006. Small scale spatial variability of organic carbon stocks in litter and solum of a forested Luvisol. Geoderma 136, 631-642.

Schuman, G.E., Janzen, H.H., Herrick, J.E., 2002. Soil carbon dynamics and potential carbon sequestration by rangelands. Environmental Pollution 116, 391-396.

van Groenigen, J.W., Siderius, W., Stein, A., 1999. Constrained optimisation of soil sampling for minimisation of the kriging variance. Geoderma 87, 239-259.

Viscarra Rossel, R.A., Walvoort, D.J.J., McBratney, A.B., Janik, L.J., Skjemstad, J.O., 2006. Visible, near infrared, mid infrared or combined diffuse reflectance spectroscopy for simultaneous assessment of various soil properties. Geoderma 131, 59-75.

Walvoort, D.J.J., Brus, D.J., de Gruijter, J.J., 2010. An R package for spatial coverage sampling and random sampling from compact geographical strata by $k$-means. Computers \& Geosciences 36, 1261-1267.

Webster, R., Oliver, M.A., 2001. Geostatistics for Environmental Scientists. John Wiley \& Sons, Chichester.

Welham, S.J., Thompson, R., 1997. Likelihood ratio tests for fixed model terms using residual maximum likelihood. Journal of the Royal Statistical Society Series B: Methodological 59, 701-714.

Wiesmeier, M., Steffens, M., Kölbl, A., Kögel-Knabner, I., 2009. Degradation and smallscale spatial homogenization of topsoils in intensively-grazed steppes of Northern China. Soil \& Tillage Research 104, 299-310.

Worsham, L., Markewitz, D., Nibbelink, N., 2010. Incorporating spatial dependence into estimates of soil carbon contents under different land covers. Soil Science Society of America Journal 74, 635-646.

Zar, J.H., 1999. Biostatistical Analysis, fourth ed. Prentice-Hall, Inc., New Jersey.

Zhou, X.-H., Gao, S., 1997. Confidence intervals for the log-normal mean. Statistics in Medicine 16, 783-790. 